\title{
Spontaneous dog osteoarthritis - a One Medicine vision
}

\author{
Richard L. Meeson ${ }^{1,2,3}$, Rory J. Todhunter ${ }^{4,5}$, Gordon Blunn ${ }^{3,6}$, George Nuki ${ }^{7}$ \\ and Andrew A. Pitsillides ${ }^{1 *}$
}

Abstract | Osteoarthritis (OA) is a global disease that, despite extensive research, has limited treatment options. Pet dogs share both an environment and lifestyle attributes with their owners, and a growing awareness is developing in the public and among researchers that One Medicine, the mutual co-study of animals and humans, could be beneficial for both humans and dogs. To that end, this Review highlights research opportunities afforded by studying dogs with spontaneous $\mathrm{OA}$, with a view to sharing this active area of veterinary research with new audiences. Similarities and differences between dog and human OA are examined, and the proposition is made that suitably aligned studies of spontaneous OA in dogs and humans, in particular hip and knee OA, could highlight new avenues of discovery. Developing cross-species collaborations will provide a wealth of research material and knowledge that is relevant to human $\mathrm{OA}$ and that cannot currently be obtained from rodent models or experimentally induced dog models of OA. Ultimately, this Review aims to raise awareness of spontaneous dog OA and to stimulate discussion regarding its exploration under the One Medicine initiative to improve the health and well-being of both species.

'Skeletal Biology Group, Comparative Biomedical Sciences, Royal Veterinary College, University of London, London, UK.

${ }^{2}$ Department of Clinical Services and Sciences, Royal Veterinary College, University of London, London, UK.

${ }^{3}$ Institute of Orthopaedics and Musculoskeletal Science, University College London, London, UK.

${ }^{4}$ Department of Clinical Sciences, Cornell University, Ithaca, NY, USA.

${ }^{5}$ Cornell Veterinary Biobank, Cornell University, Ithaca, $N Y$, USA.

${ }^{6}$ School of Pharmacy and Biomedical Sciences, University of Portsmouth Portsmouth, UK.

${ }^{7}$ Institute for Genetics and Molecular Medicine,

University of Edinburgh,

Edinburgh, UK.

*e-mail:apitsillides@rvc.ac.uk https://doi.org/10.1038/ s41584-019-0202-1
Osteoarthritis (OA) is the end point of synovial joint disease processes that interrupt the articular surface or cause instability and mechanical injury. In 2005, 26.9 million adults in the USA were estimated to have $\mathrm{OA}^{1}$, and according to a 2016 white paper from the Osteoarthritis Research Society International (OARSI), globally, OA accounted for $2.4 \%$ of all years lived with disability $^{2}$. The importance of $\mathrm{OA}$ as a global disease and a modern major health challenge therefore necessitates new research strategies.

Experimentally induced models of OA are available in many large and small animal species ${ }^{3}$. Work in the 1970s and 1980s established the clinical, biochemical and histopathological changes that are induced by cruciate ligament transection in dog stifle joints (the Pond-Nuki model) $)^{4,5}$ or by medial meniscectomy in rabbits $^{6}$. This work heralded the introduction of surgically induced OA models in small, genetically tractable species such as mice and rats. Because they are small, easy to house and relatively inexpensive, such rodent models have undeniably contributed to important advances in our understanding of basic disease mechanisms ${ }^{3}$. However, rodent models have proved to be poor predictors of the efficacy or toxicity of drugs in trials for human $\mathrm{OA}^{7}$. Rodent models of $\mathrm{OA}$ are usually either chemically induced or surgically induced; however, the veracity of the joint changes that occur following administration of intra-articular papain or monosodium iodoacetate has been questioned, and many researchers have concluded that the use of chemically induced OA should be limited to studies of joint pain ${ }^{8}$. Hence, surgical joint destabilization is the most frequently employed model. Although the value of these rapidly changing rodent $\mathrm{OA}$ models should not be underestimated, naturally occurring disease in companion animals more closely reflects the complex genetic, physiological and environmental variations that occur in human $\mathrm{OA}^{9,10}$.

Spontaneous, slow-progressing OA occurs in multiple strains of mice, as well as in guinea pigs, Syrian hamsters, non-human primates and dogs ${ }^{11}$; the histopathology and pathogenesis of dog OA most closely resemble those of primary human OA. Similar to humans, OA is also a common disease in the dog, with a prevalence that varies from $2.5 \%$ overall in UK veterinary primary care practices ${ }^{12}$ to over $20 \%$ in dogs over 1 year old in the USA $^{13}$. The clinically affected dog shares complex naturally occurring traits and comorbidities, such as obesity, that occur in humans, and both humans and companion dogs live into old age, share environments and activities and often receive almost identical treatments, such as long-term administration of anti-inflammatory drugs or joint replacement surgery. Academic and private practice veterinary medicine can provide valuable biomedical research data, as referral centres are often equipped with 


\section{Key points \\ - Dogs have many analogous spontaneous diseases that result in end-stage osteoarthritis (OA). \\ - Inbreeding and the predisposition of certain dog breeds for OA enable easier identification of candidate genetic associations than in outbred humans. \\ - Dog OA subtypes offer a potential stratification rationale for aetiological differences and alignment to analogous human OA phenotypes. \\ - The relatively compressed time course of spontaneous dog OA offers longitudinal research opportunities. \\ - Collaboration with veterinary researchers can provide tissue samples from early-stage $\mathrm{OA}$ and opportunities to evaluate new therapeutics in a spontaneous disease model. \\ - Awareness of the limitations and benefits of using clinical veterinary patients in research is important.}

Stifle joints

An analogous term for the knee joints in quadrupedal animals.

\section{Pond-Nuki model}

An experimental model of knee instability-driven osteoarthritis in dogs involving surgical cranial cruciate ligament transection.

Ortolani test Physical examination test performed in dogs and infants to assess for excessive laxity in the hip joint that allows dislocation.
MRI and CT scanners, arthroscopes and state-of-theart pathology and molecular diagnostic capabilities. Academic veterinary centres also pilot advances in the use of anti-inflammatory and pain-modulating OA drug therapies ${ }^{10,14,15}$. In this Review, we summarize research relating to common forms of spontaneous dog OA, focusing on the presentation and genetics of analogous diseases of the hip and knee, within a framework of human OA phenotypes. We also aim to encourage researchers to take on the principles of One Medicine (BOX 1) research to benefit both humans and dogs.

\section{The dog as a model animal}

The foreshortened lifespan of the dog, with its equivalent life stages to those in humans, holds potential for the longitudinal evaluation of disease and therapy in spontaneous OA (FIG. 1). Dog OA is generally considered to bear a close resemblance to human $\mathrm{OA}$ with regards to anatomic similarity, disease heterogeneity and progression $^{16}$. For example, changes in articular cartilage proteoglycans that occur in slowly progressive spontaneous dog OA (regardless of the age of the dog) closely match changes that occur in human OA but differ from those seen in rapidly advancing experimental dog OA induced by cruciate ligament transection ${ }^{17}$. Although clear anatomical similarities exist, extrapolating data from the quadrupedal dog to bipedal humans requires some caution. Indeed, the dog has comparatively reduced total joint forces that are split 60:40 between the forelimbs and hindlimbs in addition to a 20-degree flexion of the femur during the stance phase of gait, which together could have an unknown effect on OA development ${ }^{18}$.

Intriguingly, distinct OA type-specific epidemiological patterns exist in dogs, notably between breeds, and OA is clearly influenced by body size, obesity, sex, neuter status and age ${ }^{12}$. Obesity, for instance, is a known risk factor for human ${ }^{19}$ and $\operatorname{dog} \mathrm{OA}^{20}$, but evaluating its role as an independent risk factor in humans is difficult. However, work with inbred experimental dog colonies has revealed that dietary restriction reduces OA. Six week-old sex-matched and body weight-matched pairs of Labrador Retriever litter mates from closed colonies were either control fed (ad libitum) or diet restricted (75\% of control fed); radiographic hip OA was found in $25 \%$ of control-fed dogs and only $4 \%$ of diet-restricted dogs by 2 years, which increased to $39 \%$ versus $13 \%$ by
5 years and $83 \%$ versus $50 \%$ at 15 years ${ }^{21}$. Interestingly, diet restriction also extended longevity, and weight correlated only moderately with disease severity ${ }^{21}$, suggesting that other factors related to increased food intake might affect $\mathrm{OA}^{22}$. In other studies, diet restriction also reduced the severity and prevalence of shoulder ${ }^{23}$ and elbow $\mathrm{OA}^{24}$. Although the aetiology of obesity-related OA remains unclear, biomechanical effects from the overloading of weight-bearing joints have been proposed as a mechanism despite the fact that the risk of hand $\mathrm{OA}$ is also increased in obese humans ${ }^{25}$, which suggests a systemic role for obesity as a risk factor. An alternative mechanism in which adipose tissue promotes systemic low-grade inflammation via increased concentrations of adipokines has also been put forward ${ }^{26}$, and dog adipocytes are known to express important adipokines, suggesting that metabolic factors associated with being overweight or obese exert an independent risk of developing $\mathrm{OA}^{27}$.

Overall, although development of OA in dogs is likely to be more variable and protracted, and thus its study is likely to require larger numbers of animals to achieve an appropriately powered study design than rodent models, studies using these naturally occurring forms of dog OA could lead to an overall reduction in the number of animals used for experimental research and to a greater understanding of spontaneous OA. In the following sections, we outline some common forms of naturally occurring dog OA and review their suitability as models for analogous human disease (FIG. 2).

\section{Analogous dog and human disease Hip dysplasia}

Presentation. Hip dysplasia is a common risk factor for both human and $\operatorname{dog} \mathrm{OA}^{28-31}$. An estimated $20-40 \%$ of idiopathic human hip OA is caused by developmental dysplasia of the hip (DDH) $)^{32}$, with many patients requiring joint replacement later in life $\mathrm{f}^{1,33,34}$. Canine hip dysplasia (CHD) shares pathoanatomical, biochemical and clinical features with DDH and has been proposed as the best spontaneous large animal model for $\mathrm{DDH}^{17,35}$ (FIC. 3). Both DDH and CHD have delayed femoral capital ossification and an underpinning instability continuum (as detected by the Ortolani test), and severe forms are characterized by complete subluxation, focal cartilage overload and hip OA in untreated or undertreated children and $\operatorname{dog}^{34,36-38}$ (FIG. 3b,c). DDH and CHD are morphologically similar; for example, collagenous fibrils in the articular cartilage of patients with DDH are sparse and disordered and closely resemble changes to the cartilage ultrastructure seen in $\mathrm{CHD}^{39,40}$. Many older dogs that had no indication of joint laxity or osteoarthritic change at 2 years (early adulthood) develop OA as they age, which resembles human acetabular dysplasia and secondary $\mathrm{OA}^{41,42}$ (FIG. 3d,e).

Although other forms of hip OA are potentially more common than CHD and DDH, these forms might not be analogous in dogs and humans. For example, femoroacetabular impingement (FAI), in which a thickened, aspherical femoral head-neck junction results in abutment against the acetabular labrum joint ${ }^{43}$, is thought to be a common cause of hip pain in human hip OA. By contrast, 


\section{Box 1 | One Health, One Medicine and veterinary medicine}

The One Health concept, in which human health is recognized as being closely connected to animal health and the environment, dates back to Hippocrates and Aristotle. Claude Bourgelat, a founder of 18 th century veterinary medicine, advocated this intimacy ${ }^{226}$, which was further emphasized by the 19th century physician Rudolf Virchow, who coined the term 'zoonosis' upon discovering that Trichinella spiralis from pigs causes human neurocysticercosis ${ }^{227}$. Despite historical recognition of the One Health concept, a culture of marked anthropocentricity emerged during the 1970s, shifting research emphasis towards induced, experimental animal models of disease.

One Health approaches regained momentum following outbreaks of the highly pathogenic $\mathrm{H} 5 \mathrm{~N} 1$ avian influenza in 1996 and of corona virus-associated severe acute respiratory syndrome (SARS) in 2003. Distinct from One Health, One Medicine is now emerging as a holistic paradigm wherein veterinary and human medical researchers and clinical practitioners collaborate to increase their understanding of shared diseases and to develop new therapies ${ }^{228}$. Companion animals are a large population, with $\sim 70$ million pet dogs living in the USA alone ${ }^{226}$. Dogs typically live into old age, come in a variety of shapes and sizes (from highly athletic to sedentary and overweight) and live in close proximity to humans. As dogs develop many age-related chronic diseases and comorbidities on a foreshortened timescale (breed-influenced life expectancy is $\sim-12$ years) that are analogous to those in humans, there is a growing view that developing our understanding and treatment of dog osteoarthritis (OA) could lead to breakthroughs in human $\mathrm{OA}^{153}$.

\section{Norberg angle}

An angle based upon a

radiographic measure of a line that connects the centres of

both femoral heads and the craniodorsal rim of the

acetabulum on the same side; used as a surrogate measure of hip laxity and femoral head coverage by the acetabulum. the existence of FAI in the dog is uncertain, although whether FAI has simply not been looked for, or is not specifically recognized in the dog, is somewhat unclear.

Genetics. DDH occurs in between 1 and 20 live births per 1,000 worldwide ${ }^{44}$, and predisposing factors include family history, being a first born, female sex and breech birth $^{45,46}$. Familial segregation studies ${ }^{47,48}$ suggest that $\mathrm{DDH}$ has a multifactorial genetic basis, but statistical support for this theory varies across populations and countries ${ }^{49}$. For example, in a Chinese population, the recurrent risk of DDH in the siblings of affected individuals was approximately tenfold greater than in controls and had a heritability of $\sim 85 \%{ }^{47}$. By contrast, the frequency of CHD varies between different dog breeds, reaching a peak of $\sim 75 \%$ in Golden Retrievers and Rottweilers ${ }^{50}$, and shows no sex predilection in most breeds; the exception is Polish Tatra Sheepdogs, in which the risk of CHD in females is greater than threefold the risk in males ${ }^{41}$. This intra-breed and inter-breed variation is proving valuable in identifying the genetic basis of CHD. CHD demographics most closely mirror $\mathrm{DDH}$ in late-onset acetabular dysplasia ${ }^{41}$. CHD heritability ranges from $20 \%$ to $60 \%{ }^{51}$, and evidence from multipoint linkage studies and genome-wide association studies (GWAS) ${ }^{52-59}$ suggest that 5-10 quantitative trait nucleotides of modest effect control $\mathrm{CHD}^{60}$.

Approximately 15 genes with known functions in embryonic patterning and extracellular matrix (ECM) structure and remodelling have been associated with $\mathrm{DDH}$ and hip OA, predominantly via screening for candidate genetic polymorphisms ${ }^{61}$. Many genetic associations lack replication, with the exception of CX3CR1 (encoding the G protein-coupled receptor CX3-chemokine receptor 1 (CX3CR1); also known as fractalkine), which was first identified by linkage mapping and exome sequencing ${ }^{62,63}$, with a single nucleotide polymorphism (SNP) being subsequently linked independently with $\mathrm{DDH}^{64}$. CX3CR1 is involved in mesenchymal stem cell recruitment to the joint ${ }^{62,65}$, and Cx3cr1-knockout mice develop acetabular dysplasia ${ }^{66}$. The association between DDH and GDF5 has also been replicated in a GWAS using data from the UK Biobank ${ }^{67}$.

Whereas a genetic basis for DDH is likely, but not certain $^{67,68}$, it is undisputed in $\mathrm{CHD}^{69}$. An intronic deletion in FBN2 was associated with CHD in a linkage analysis of a direct hip laxity trait (the hip distraction index), and FBN2 mRNA was upregulated in tissue samples from dysplastic dog hip joints ${ }^{70}$. CHD-associated loci identified by a GWAS of Labrador Retrievers in the UK (>1,000 dogs) include those on canine chromosome 01 (CFA01) and CFA21 (REF. ${ }^{55}$ ). Another GWAS that used several breeds of dog identified an SNP in CTBP2 on CFA28 that was linked to CHD, specifically the Norberg angle ${ }^{52}$. This SNP and SNPs at two more loci near TRIM2 and DPP4 were subsequently associated with CHD in a post hoc analysis of the same data ${ }^{53}$. However, similar to genetic studies of DDH, GWAS of CHD have also been difficult to replicate across different breeds and laboratories ${ }^{55}$. Large-scale association studies indicate that the vast majority of significantly associated variants reside outside of protein-coding exons, which make up only $1.2 \%$ of the human genome ${ }^{71}$, a situation that is likely to be similar in the dog genome. Because not all structural variants, including deletions, duplications, inversions and translocations, in non-coding regions of the genome might be tagged by an SNP, genetic causes of complex trait variation will often be missed in GWAS. For example, in a study of 4,200 genotyped dogs, most variants were poorly tagged by markers in a high-density mapping array of $>180,000$ markers $^{52}$; other previous canine GWAS are also likely to have causal variant mutations. Whole genome sequencing and genotype imputation are probably needed to capture all causal mutations in canine GWAS.

Intriguingly, in a 2014 study, three human patients with sporadic DDH shared an identical frameshift mutation in ZRANB1 $\left(\mathrm{REF}^{63}{ }^{63}\right.$ ), which is notable, as ZRANB1 is in the same canine linkage disequilibrium interval as the CTBP2 SNP on CFA28 (REF. ${ }^{52}$ ). A locus on CFA37 in Bernese Mountain Dogs has also been associated with CHD and lies near FN1, which is associated with human $\mathrm{DDH}^{59}$. These genetic similarities indicate that studying CHD in selected breeds of dog, such as Labrador Retrievers, Golden Retrievers or Rottweilers, could yield novel mechanistic insights into the aetiopathology of hip dysplasia in dogs and humans (FIG. 2). As strong evidence exists for similarities in the phenotype and progression of secondary OA in dysplastic hip joints in humans and dogs, parallel genomic, transcriptomic and methylomic biomarker analyses in both species are likely to be highly informative. Fresh samples can be retrieved readily from dogs undergoing joint salvage procedures, which could facilitate transcriptional screening to overcome the replication barrier, as genetic associations are likely to have been previously missed.

Using CHD as a means to understand DDH. Does CHD occur with sufficient predictability to provide a feasible model for DDH? CHD occurs with $75 \%$ prevalence in Golden Retrievers and Rottweilers ${ }^{50}$. As in humans, 


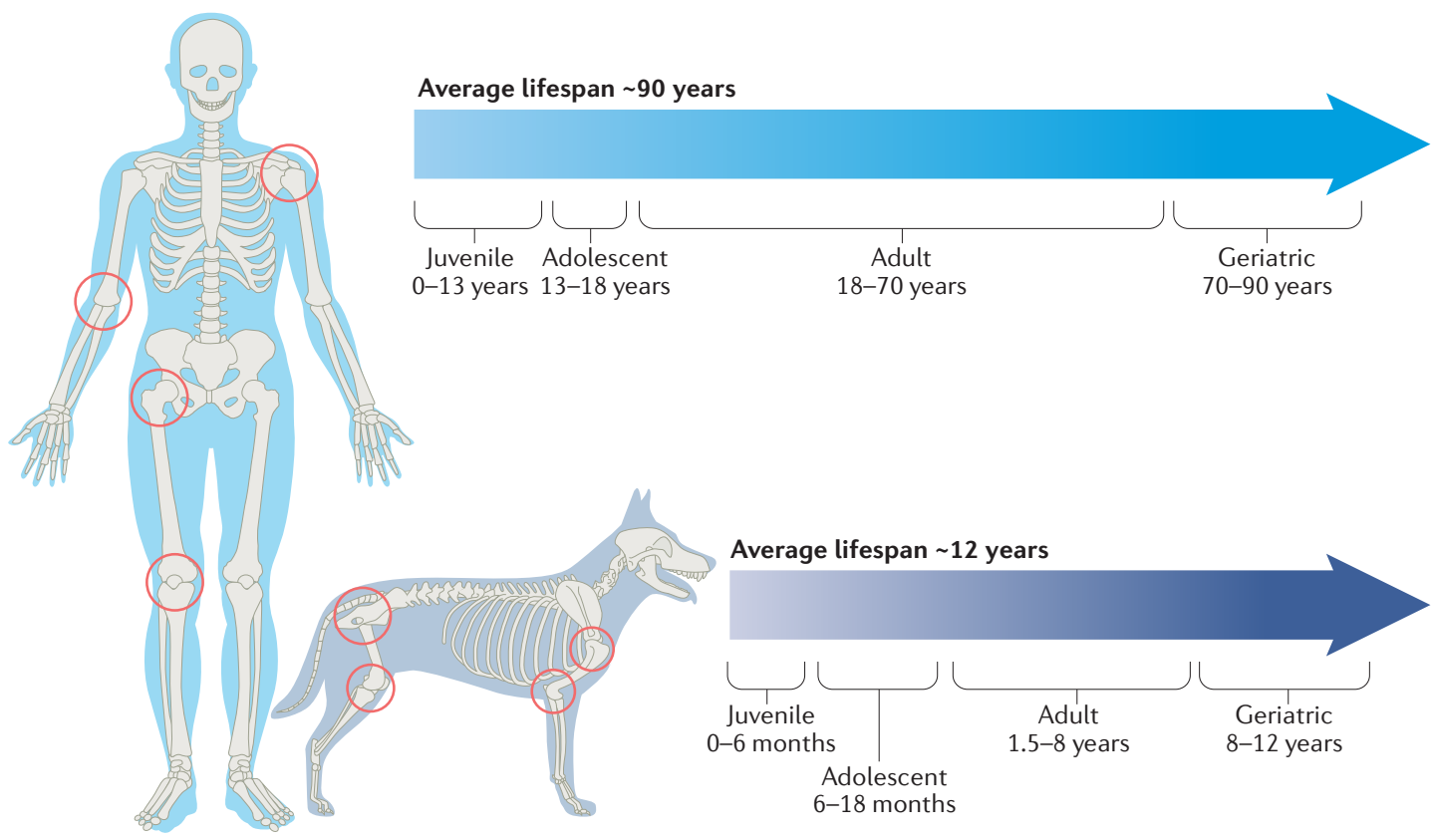

Fig. 1 | Osteoarthritis in dogs and humans. The most common locations for osteoarthritis in dogs include the knee, hip, shoulder and elbow, which are shown with their homologous equivalent in humans. The average lifespan of a large-breed $\operatorname{dog}$ is $\sim 12$ years, with a proportionately longer time spent in old age than in a typical human lifespan.

this high prevalence has heralded early-stage hip laxity screening in these breeds $s^{72}$ and health improvement programmes that include novel laxity measures (the PennHIP distraction view to calculate the distraction index), which enable the identification of dogs at the age of 4 months that are highly unlikely to develop OA by the age of 3 years $^{73}$. CHD resembles DDH clinically and pathologically but progresses over a compressed time frame, adding to its utility as a model. Many dog screening programmes and registries employ traditional hip extended pelvic radiography (FIG. 3a), and some have DNA banks (such as the Canine Health Foundation of the American Kennel Club), which presents an opportunity to identify genetic, epigenetic or environmental factors common to DDH and CDH. The phenotypic characteristics of these two diseases are similar enough to warrant simultaneous clinical and basic research to augment progress in treatment and prevention of dog and human hip OA secondary to dysplasia. Current treatment strategies for hip dysplasia in dogs and humans are highlighted in BOX 2. Researchers have also explored the role of fetal movement in the development of bone shape in patients with DDH using $\mathrm{MRI}^{74}$. Although the cost of such MRI studies is currently prohibitive in dogs, the possibility of a One Medicine approach to advance research in this field by careful fetal tracking of the developmental emergence of joint incongruity in $\mathrm{DDH}$ and $\mathrm{CDH}$ is worth considering.

\section{Knee cruciate ligament rupture}

Presentation. Dog knees have human-like anatomy ${ }^{75}$ including an anterior cruciate ligament (ACL) that is termed the cranial cruciate ligament (CCL) in dogs owing to their quadrupedal arrangement (FIG. 4). Experimentally, dogs have been used for several surgical models of OA, including CCL transection ${ }^{4}$, partial transection $^{76}$, synovial debridement ${ }^{76}$, transarticular impact ${ }^{77}$, tibial osteotomy ${ }^{78}$, meniscal sectioning ${ }^{11}$ and articular cartilage scarification ${ }^{79}$. In humans, ACL rupture can lead to $\mathrm{OA}^{80}$, and the same is true in $\operatorname{dogs}^{81}$. Spontaneous CCL rupture (FIG. $4 b, d, h$ ) is common in dogs, and certain breeds such as West Highland White Terriers, Staffordshire Bull Terriers, Retrievers and Rottweilers are particularly predisposed ${ }^{82,83}$. Analogous CCL transection is well documented to cause inflammation and reparative responses in the cartilage and synovium, yet ongoing instability prompts cartilage erosion and subchondral bone changes, thereby mirroring spontaneous knee $\mathrm{OA}^{84}$. Spontaneous knee OA has a prevalence of $\sim 20 \%$ in some breeds of $\operatorname{dog}^{85}$, and $\sim 50 \%$ of commonly affected breeds, such as Labrador Retrievers, develop contralateral knee CCL rupture within 1 year of diagnosis ${ }^{86}$. Despite its ubiquity, the underlying cause of breed predilection remains elusive; biological and biomechanical explanations have been suggested, including the slope of the tibial plateau, intercondylar fossa impingement, underlying immune-mediated pathology, hormonal influences and genetics $^{82,87}$. Notably, the spontaneous rupture of a dog CCL often occurs during normal activities, such as walking or running. By contrast, human ACL rupture occurs most commonly during sporting activity ${ }^{88}$. Although the underlying mechanisms of CCL pathology are undefined, predisposed dogs have thinner collagen fibrils in weaker CCLs that have increased expression of matrix metalloproteinase 2 than those of cruciate disease-resistant breeds such as Greyhounds ${ }^{82}$. Importantly, although ACL rupture in young humans is generally considered to be traumatic in cause, $\sim 70 \%$ of macroscopically normal human ACLs also have histological evidence of pathology consistent with early degeneration ${ }^{89}$. 
Genetics. Non-contact rupture of a human ACL (such as occurs during pivoting and landing manoeuvres when playing sport), as distinct from a direct high energy impact to the knee, has a complex aetiology. As in the $\mathrm{dog}$, variation in outcome is influenced by age, sex, genetics, obesity, muscle strength, activity and re-injury ${ }^{90}$. Young female athletes have a threefold to sixfold higher risk of ACL injury than their male counterparts ${ }^{91}$. The risk of ACL injury is doubled in individuals with similarly affected relatives ${ }^{92}$ and is also raised in white individuals ${ }^{93}$, suggesting the presence of sex-linked and genetically linked human determinants. Polymorphisms in FBN2, VEGFA, KDR, COL1A1, DCN, ACN (also known as ACIN1), BGN, LUM and COL5A1 (many of which encode ECM proteins and growth factors) and interactions between COL5A1 and COL12A1 gene variants $^{94}$ are linked to human ACL rupture ${ }^{95-99}$. Genetic associations with human ACL rupture found a COL1A1 SNP that was replicated in several studies ${ }^{98,100-104}$.
A systematic review ${ }^{100}$ was followed by a GWAS that failed to reveal any ACL rupture-associated variants, highlighting the fact that replication and cross-species overlap will be mutually supportive in the investigation of complex traits.

Five-year-old dogs consistently have degenerative changes in their CCLs at both the macroscopic and microscopic levels (FIG. 4b). Susceptibility to CCL rupture is increased in Labrador Retrievers and Golden Retrievers, and the CCLs of these breeds have higher collagen turnover, less stiffness and less mature collagen crosslinks than the CCLs of Greyhounds, which are relatively rupture resistant ${ }^{82}$. The genetics of dog CCL rupture are complex; a $0.15-0.27$ heritability exists in Newfoundlands, which have four putative quantitative trait loci (QTLs) by linkage analysis ${ }^{105}$ and non-overlapping associations on CFA01, CFA03 and CFA33 by GWAS $^{106}$. A case-control comparison across four breeds revealed SNPs in genes involved in ligament

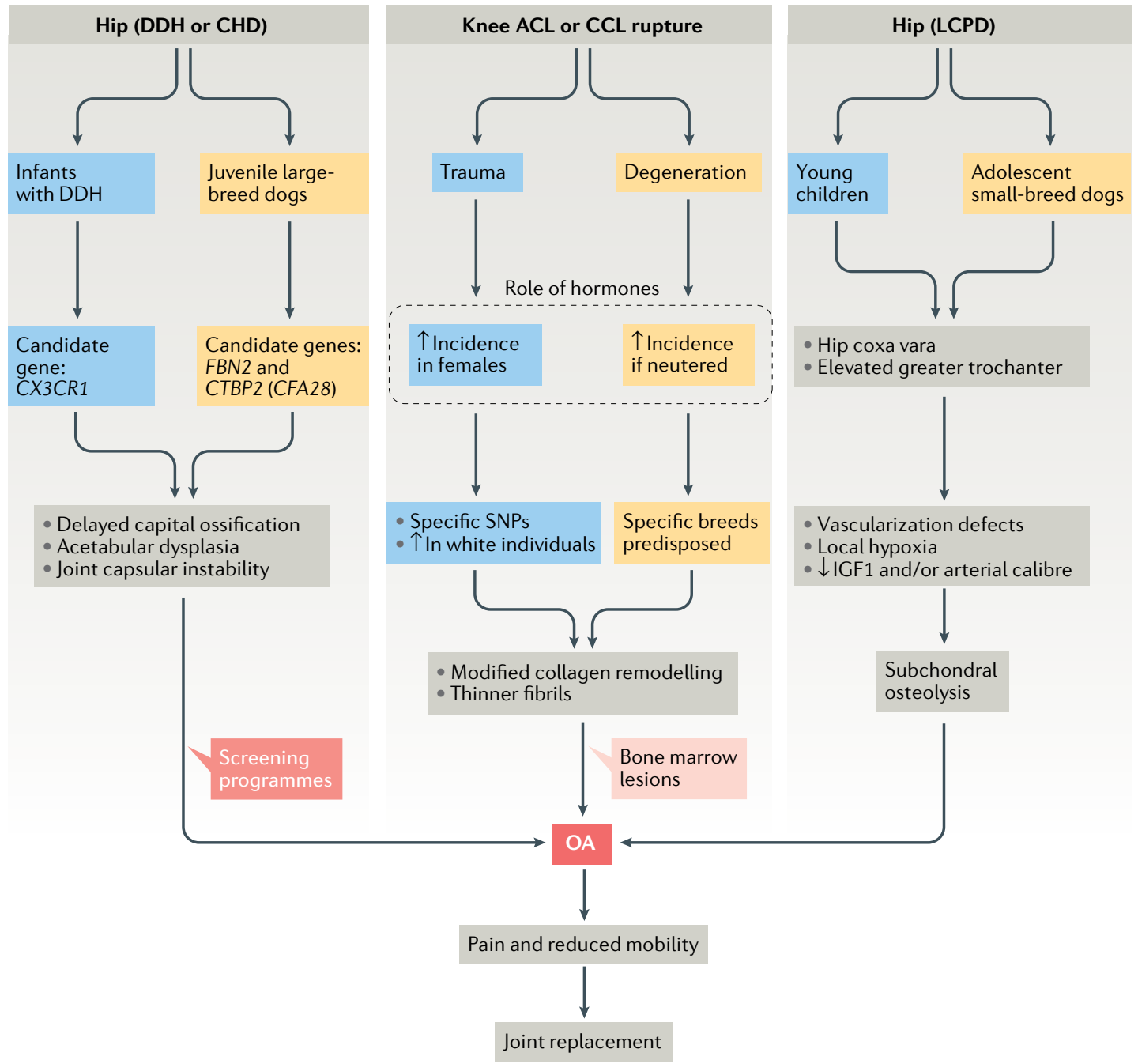

Fig. 2 | Analogous disease in dogs and humans. Similarities in the aetiopathology of dog (yellow) and human (blue) forms of osteoarthritis (OA) are shown for developmental vascular OA of the hip (Legg-Calvé-Perthes disease (LCPD) in dogs and LCPD and avascular necrosis of the femoral head in humans), developmental joint instability OA (canine hip dysplasia (CHD) in dogs and developmental dysplasia of the hip (DDH) in humans) and acquired adult joint instability OA (knee anterior cruciate ligament (ACL) rupture in humans and cranial cruciate ligament (CCL) rupture in dogs). IGF1, insulin-like growth factor 1; SNP, single nucleotide polymorphism. 
ECM composition and strength that were associated with susceptibility to CCL rupture ${ }^{107}$. Subsequent studies reported significant associations on CFA7-9 in several dog breeds ${ }^{53}$ and genome-wide significance for CFA24 in ACL ruptures in Labrador Retrievers ${ }^{108}$. This lack of replication is probably caused by limitations similar to those for CHD. Functional studies that utilize relevant temporal tissue samples from dog OA at various stages to identify expression QTLs that overlap with genomic QTLs will be necessary to establish causation (FIG. 2).

Using CCL rupture as a means to understand ACL rupture. Spontaneous CCL rupture might be analogous to experimental transection in dogs, as osteophytes and sclerosis develop at an early stage ${ }^{81}$ and end-stage OA develops over several years ${ }^{109,110}$ (FIG. 4d). However, the aetiology is likely to differ, as the CCL ruptures at its mid-substance during normal activity, which is often linked with prior degeneration and moderate to severe $\mathrm{OA}^{82,87}$. Although CCL transection induces synovitis, lymphocytic-plasmacytic synovitis also occurs in spontaneous CCL rupture ${ }^{111,112}$. The propensity for bilateral
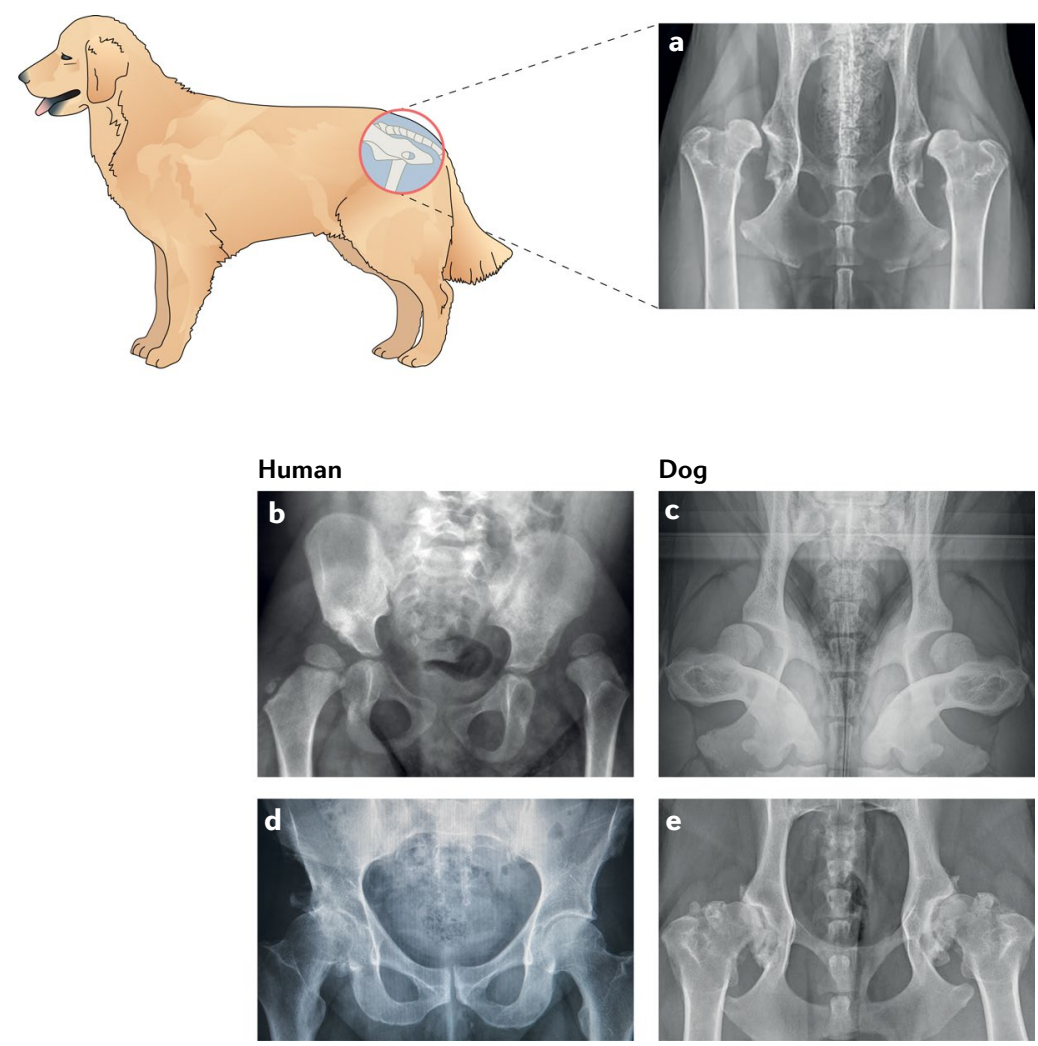

Fig. 3 | Hip dysplasia and hip osteoarthritis in dogs and humans. Hip dysplasia commonly occurs in juvenile large-breed dogs, such as Golden Retrievers, and can result in osteoarthritis $(\mathrm{OA})$ in later years. a | Radiograph of an adult dog with severe hip dysplasia and luxated hips. The image was acquired as a ventrodorsal extended limb radiograph. $\mathbf{b} \mid$ Radiograph of a human infant with a dysplastic luxated left hip. c| Radiograph of a 3-month-old dog with bilateral dysplastic and subluxated hips. The image was acquired in a dorsolateral subluxation screening position. d,e $\mid$ Radiographs of the hip joints from a middle-aged male human with primary OA (part d) and a middle-aged female large-breed dog with secondary OA subsequent to hip dysplasia (part e). Both human and dog osteoarthritic hips show evidence of advanced new bone formation and sclerosis of the acetabulae and the femoral head and neck region. Part $\mathbf{b}$ courtesy of R. T. Loder, Riley Children's Hospital, USA. disease to develop following CCL rupture has enabled investigation into early-stage and incipient disease, which has intriguingly revealed increased numbers of $\mathrm{CD}^{+}, \mathrm{CD}^{+}$and $\mathrm{CD}^{+}{ }^{+} \mathrm{CD} 4^{-} \mathrm{CD} 8^{-} \mathrm{T}$ cells in dogs with CCL ruptures compared with healthy controls, with the number of $\mathrm{CD} 3^{+} \mathrm{CD} 4^{-} \mathrm{CD} 8^{-} \mathrm{T}$ cells correlating inversely with radiographic severity ${ }^{113}$. Similar to the M1-like macrophage polarization that occurs in human knee $\mathrm{OA}^{114}$, preliminary data suggest that dog joints with CCL rupture also exhibit an M1-like macrophage polarization, whereas M2-like macrophages predominate in healthy joints ${ }^{115}$. The predictability of contralateral disease development in dogs with ruptured CCLs has also offered unique opportunities for biomarker studies, which have revealed an increase in IL-8 concentrations in synovial fluid before CCL failure ${ }^{116}$. Changes identifiable on MRIs of partially ruptured dog CCLs might also improve our understanding of OA progression ${ }^{117}$. However, owing to the differing pathogenesis of rupture, it remains to be seen whether changes predicted by incipient contralateral disease in dogs are recapitulated in human OA.

Comparisons between OA associated with dog CCL rupture and OA associated with human ACL rupture might also help to explain the relationships that exist between hormonal status and OA. Oestrogen reduces collagen synthesis in fibroblasts from human ACLs in vitro ${ }^{118,119}$, and the risk of ACL rupture in female human athletes is increased on the first days of the menstrual cycle ${ }^{120}$. Likewise, the commonplace neutering of dogs increases CCL rupture risk, as does being female and being overweight ${ }^{83,121}$. Hence, examination of the at-risk female dog might offer insight into the function of hormones or post-neutering weight gain ${ }^{122}$. A more complete understanding of the similarities and differences between OA related to dog CCL rupture and OA related to human ACL rupture might reveal the hormonal influences that underpin the markedly higher primary human knee OA incidence in postmenopausal females than in age-matched men ${ }^{123}$.

We are not arguing that human and dog cruciate ligament ruptures have identical causes nor identical management strategies (BOX 3) but instead aim to highlight that both involve mechanical instability and intractable progression to knee OA, thereby making simultaneous research in both species potentially beneficial.

\section{Other conditions of interest}

Osteochondritis dissecans. Dog shoulders develop both age-related primary $\mathrm{OA}^{23}$ and osteochondrosis, which presents as osteochondritis dissecans lesions ${ }^{124}$ (FIG. 5) that are characterized by disordered endochondral ossification superimposed upon previously normal growth $^{125-127}$. Osteochondrosis predominates in medium and large breeds of dog, affects males more frequently than females and is often bilateral and site-specific ${ }^{128}$. Intriguingly, male humans are also more frequently affected with osteochondrosis, and bilateral disease is also common ${ }^{129,130}$. Unilateral osteochondrosis in young dogs enables tissue samples of early contralateral lesions to be collected and arthroscopic autologous or biomaterial articular resurfacing to be carried out ${ }^{131,132}$. 


\section{Box 2 | Clinical treatment of dysplastic hips}

Treatment options for canine hip dysplasia (CHD) and developmental dysplasia of the hip (DDH) consist of similar symptom management, hip reconstructions and replacement methods. Radiographic images show a human total hip replacement using an uncemented stem and cup (see the figure, part a) and a dog total hip replacement using a cemented stem and uncemented cup (see the figure, part b). Trait similarities and a relatively truncated dog lifespan will probably make the discovery of common early features of hip osteoarthritis (OA) more rapid in dogs with CHD than in humans with DDH. The dog is also an excellent model for human total hip replacement ${ }^{202,229}$. Both dogs and humans have similar bone remodelling characteristics and respond well to hip replacement for non-responsive and debilitating end-stage $\mathrm{OA}^{201,224,230}$. The treatments for $\mathrm{CHD}$ and DDH use similar clinical and functional measures, including gait analysis and accelerometer measurements, validated clinical questionnaires and imaging techniques ${ }^{168,229,231,232}$.
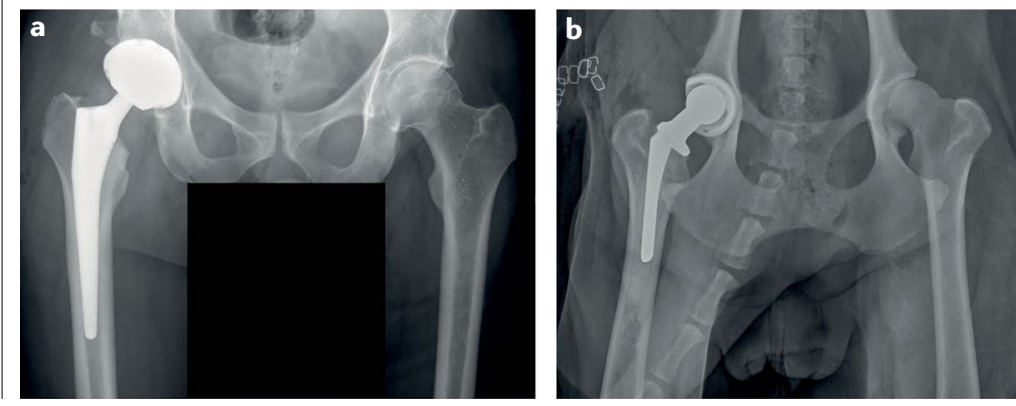

Aberrant re-induction of endochondral ossification processes has been described in articular cartilage in several forms of human and mouse $\mathrm{OA}^{133,134}$, and it is therefore intriguing that the dog shoulder is targeted in this particular way, much more so than in the human.

Control of endochondral ossification differs markedly in different breeds of dog, which can have an astounding several-fold size variation and differ in growth rate and/or physeal closure at puberty. Earlier physeal closure in small breeds is consistent with more rapid growth and potential predisposition to osteochondritis dissecans. Growth plates in large breeds, such as Great Danes, have an expanded hypertrophic region and more active bone morphogenetic protein 2 (BMP2)BMP6 signalling than miniature breed $\mathrm{s}^{135}$, suggesting that studies of osteochondritis dissecans could provide unique insights into the function of longitudinal bone growth in these disease processes. Another possible connection has emerged from studies that established direct links between genetic selection for high growth rates, failure of mechano-adaptive bone changes and predisposition to skeletal diseases in birds ${ }^{136,137}$. Whether similar relationships persist in dogs and humans has yet to be explored.

Legg-Calvé-Perthes disease. Legg-Calvé-Perthes disease (LCPD), a form of avascular necrosis of the femoral head, involves slow femoral head destruction in children. LCPD has a direct analogue in small-breed dogs (FIG. 6), such as Yorkshire Terriers, Maltese, Miniature Poodles and Chihuahuas, during early life that peaks at skeletal maturity (6-7 months) ${ }^{124}$. Bilateral hip OA is common in human LCPD, peaking at 4-8 years of age, and occurs approximately four times more frequently in boys than in girls ${ }^{138}$. By contrast, no sex bias for LCPD exists in dogs, and the trait is often unilateral ${ }^{124}$. Familial and isolated human LCPD occurs with an estimated $\sim 0.84$ heritability in relatives of probands (first affected family member) ${ }^{139-141}$ and has links to environmental and demographic factors ${ }^{142}$. A similarly high degree of heritability was found in an experimental pedigree of Manchester Terriers ${ }^{143}$. Further genetic studies have been described in both dogs and humans, with intriguing differences and similarities ${ }^{144-148}$, discussion of which is beyond the scope of this Review.

\section{A One Medicine approach}

The idea that OA is not one disease but a syndrome encompassing heterogeneous, stratified groups of patients with characteristic aetiologies has been gaining acceptance. This shift in thinking has led to an increased appreciation that the development of new targeted therapeutic approaches might be accelerated by patient stratification on the basis of phenotype (or endotype), which might also improve alignment with preclinical animal models. An initial attempt at disease stratification of patients with knee OA proposed five OA phenotypes, which are defined by the severity of joint involvement, muscle strength, obesity and depres$\operatorname{sion}^{149}$. A subsequent systematic review ${ }^{150}$ identified six phenotypic groups: those with central chronic pain sensitization; inflammation; systemic metabolic changes; bone and/or cartilage remodelling; mechanical overload with varus deformity and compartment diseases; and minimally symptomatic OA. OARSI suggests five clinically distinct phenotypes that are based on presentation with pain sensitization, psychological distress, radiographic severity, BMI, muscle strength, inflammation and comorbidities ${ }^{151}$. Another systematic review of knee OA identified obesity and other metabolic abnormalities, sex, cartilage damage patterns and inflammation as variables upon which distinct structural OA phenotypes could be delineated ${ }^{152}$. We conjecture that the common dog OA types we have highlighted herein provide models for ready alignment with human OA on the basis of anatomy, aetiology and pathophysiology (TABLE 1) and propose a system for their use with a view to analogous human OA.

\section{Advantages}

Is there any prospect that the study of spontaneous dog OA might accelerate new developments in human OA? Currently, cancer research is the field that has most readily adopted and successfully applied a One Medicine approach. Cancers account for $>25 \%$ of dog mortalities $^{153}$ and, like OA, the multifactorial and complex aetiology of cancer reduces the predictive value of rodent models. The Canine Comparative Oncology Genomics Consortium initiated an extensive, naturally occurring canine cancer tissue bio-repository. Partnerships between veterinary and human oncologists and biologists subsequently generated a Comparative Oncology Trials Consortium ${ }^{10}$, which rapidly discovered new facets of carcinogenesis ${ }^{154,155}$ that could be translated into human trials ${ }^{156}$. From the diseases highlighted in this Review, we outline five clear opportunities provided by adopting a similar One Medicine approach in OA research. 

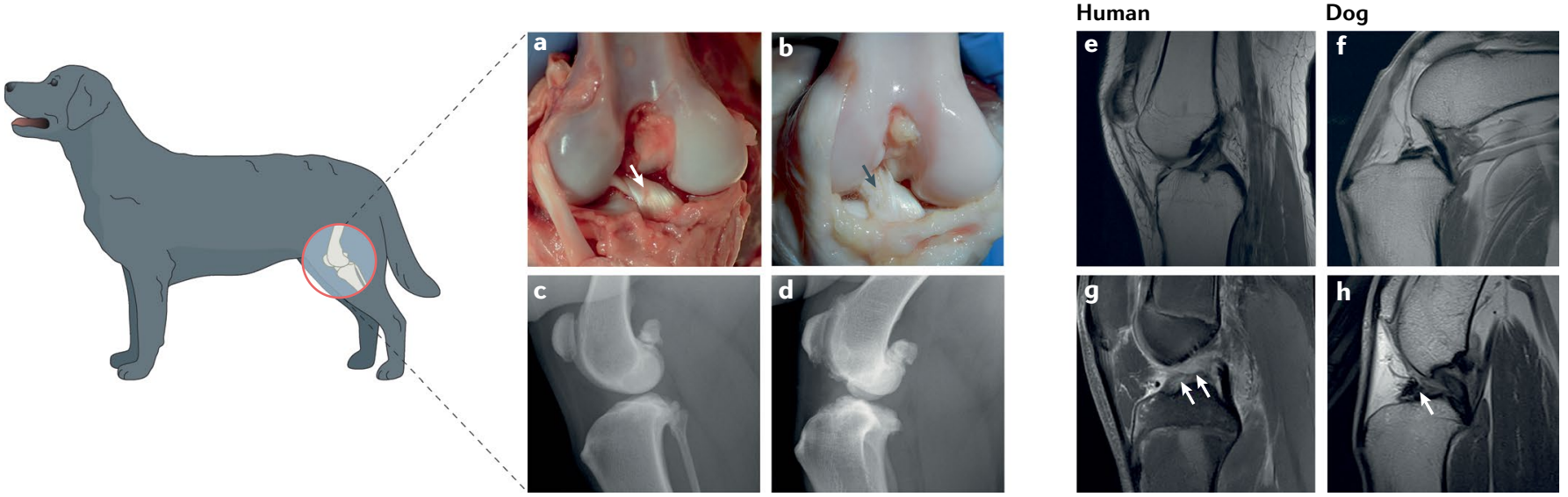

Fig. 4 | Cruciate ligament rupture and knee osteoarthritis in dogs and humans. Cranial cruciate ligament (CCL; analogous to the human anterior cruciate ligament (ACL)) rupture occurs in most breeds of dog but is particularly common in young large-breed dogs, such as Labrador Retrievers, and older small-breed dogs. a| Post-mortem dog knee with a healthy CCL (arrow). b | Post-mortem dog knee with a spontaneously degenerated, partially ruptured CCL (arrow shows degeneration of the craniomedial (anteromedial) band). $\mathbf{c}$ | Mediolateral radiograph of a healthy dog knee that shows no signs of effusion, sclerosis, soft tissue thickening or osteophytosis. $\mathbf{d}$ | Mediolateral radiograph of a dog knee with a ruptured CCL and osteoarthritic changes. Radiographic joint effusion and new bone formation associated with the distal pole of the patella, the tibial plateau, trochlear ridges and the insertion of the CCL are evident. e $\mid$ Proton density turbo spin echo sequence sagittal MRI of a healthy human knee. $\mathbf{f} \mid \mathrm{T} 1$-weighted sagittal MRI of a healthy dog knee showing the CCL in part and the caudal cruciate ligament in full. $\mathbf{g} \mid \mathrm{MRI}$ of an adolescent human knee with a ruptured $\mathrm{ACL}$ (arrows indicate the space without an intact ligament). $\mathbf{h} \mid$ MRI of a dog stifle joint with a ruptured CCL (arrow indicates space without a CCL). Part e courtesy of K. Chappell, Imperial College London, UK.

A source of tissue for research. From the examples provided in the proposed OA sub-categorization (TABLE 1), researchers could identify a clinical dog syndrome and then perform studies to verify the validity of the alignment we propose. For example, such an approach could involve an exploration of whether two distinct subgroups of patients with symptomatic knee OA exist in dogs on the basis of inflammatory gene expression profiles in peripheral blood leukocytes ${ }^{157}$ or whether dogs have alternative metabolic or cell senescent mechanistic OA phenotypes ${ }^{152}$. In addition, clinical samples such as fragments of osteochondritis dissecans lesions, resected ruptured CCL remnants, excised damaged menisci, or plasma, urine or synovial fluid samples could be retrieved for biomarker assessment as part of the clinical disease management of a dog. Dogs with unilateral CCL disease often have premonitory radiographic and clinical signs of synovial effusion, and partial CCL tears are often associated with painful lameness in affected dogs, even when instability is minimal. Measuring soluble biomarkers in biological fluids might therefore facilitate early diagnosis or evaluation of interventions ${ }^{158}$. Similarly, resected osteoarthritic femoral heads and synovium from hip replacement procedures could be used to facilitate a greater understanding of OA mechanisms and could perhaps be used to improve diagnostic and prognostic criteria.

The correlation of arthroscopic, surgical and advanced imaging data with stage-specific changes in tissue samples taken from dogs with specific OA phenotypes would also be possible, for example, correlating analyses of synovial fluid and serum samples with clinical joint scores in dogs with CCL rupture. Similar correlations have previously been performed in experimental models of OA but could also be evaluated in spontaneous dog OA with appropriate staging and radiographic scoring ${ }^{11,159-162}$. Dog joints enable longitudinal study using modern imaging techniques (such as CT, MRI and arthroscopy), serial force plate analysis and tissue sampling and have the potential to reveal additional insights into $\mathrm{OA}$ at early and late stages compared with mouse models of $\mathrm{OA}$, in which such evaluations are not technically feasible. Indeed, tissue sampling could be included as part of a clinical trial as soon as clinical, radiographic, CT or MRI evidence of abnormal joint architecture is identified. Gaining usable samples of sufficient quantity is a practical possibility when working with dogs with spontaneous OA through schemes such as the Cornell Veterinary Biobank or the Vetmeduni Vienna VetBiobank.

A means to identify the genetic basis of analogous disease. The study of purebred dogs lends itself to the genetic analysis of complex diseases such as hip dysplasia, osteochondritis dissecans and LCPD. Residual blood collected for routine haematology or biochemistry tests in the clinic could be used for many purposes, including as a source of DNA for genetic research; removed tissues could also be utilized for such studies. Making use of the broad linkage disequilibrium introduced by selective breeding in breeds with a high predilection for a disease compared with breeds with a low predilection for a disease will help to identify common candidate disease-associated genes in these polygenic conditions.

A source of clinically applicable functional outcome measures. One clear difference between dogs and humans is the ability to self-report pain. As subjective pain measures can be readily quantified in humans, 
Telemetric accelerometry A device that measures and records proper acceleration; used to determine activity and gait parameters.

Quantitative Sensory Testing

A non-invasive test of nerve function and/or pain that uses temperature or skin vibration.

Peak vertical force

A biomechanics term that identifies a component of locomotor ground reaction force.

'Three Rs' agenda

An initiative to improve the use of or reduce the numbers of animals used in scientific research through three key initiatives - replacement, reduction and refinement. objective data have been used sparingly ${ }^{163}$. Instead, clinical metrology instruments and a patient-centred approach to outcome assessment have become mainstays in the assessment of human OA. A patient-centred approach has also been incorporated into veterinary assessments; clinical metrology instruments and validated outcome questionnaires are used to capture pain-related behaviour over long periods of time in home environments ${ }^{164}$, and pet owners can provide proxy assessments, just as parents or caregivers would for young children or adults with dementia ${ }^{165,166}$. Although objective assessment methods are less readily available than proxy reporting, these instruments have been validated, they are inexpensive and are straightforward to use, the data they produce are easy to analyse, and they do not have the relevancy issues associated with proxy reporting. Instruments such as the Canine Brief Pain Inventory ${ }^{167,168}$, which is analogous to the human Brief Pain Inventory, have the potential to expand the ability to gain outcome assessment data from veterinary clinical trials. Such inventories (including the Liverpool OA in Dogs index ${ }^{169}$ ) have to be valid, reliable and responsive to clinical change; measure what they seek to measure; be validated against a gold standard, such as force plate analysis; and demonstrate reliability to generate the same outcome whenever an individual with unchanged disease is re-assessed ${ }^{167,169}$. The power of such inventories has been verified for outcomes such as disturbed sleep in dogs with $\mathrm{OA}^{170}$.

The size of a dog compared with rodents enables different types of functional outcome assessments to be used, many of which are clinically applicable to humans. Although many veterinary researchers use visual lameness and clinical pain assessments (which report only single outcome measures), force plate analysis and radiography are also used ${ }^{171}$, which has led to objective force plate outcome measurement becoming a common gold standard for functional assessment in dogs. Kinematic evaluation, as well as the more commonly used kinetic gait analyses using force plates and pressure mats, provides objective snap shots of impairment ${ }^{172,173}$, and the size and amenable nature of dogs make them suitable for such assessments ${ }^{173,174}$. Additionally, the introduction of miniaturized data recording technology has made telemetric accelerometry and activity monitoring practical in the clinical setting ${ }^{175}$. These objective assessments are less expensive and less complicated to use than force plates and offer easy longitudinal assessment for OA interventions and disease progression ${ }^{174-177}$. Many other tests could be useful in OA monitoring, including thermal imaging and mechanical nociceptive threshold testing ${ }^{178,179}$. Functional activity monitoring, force plate analysis and advanced MRI are performed on dogs in a manner that mirrors their use in human patients, and brain imaging in conscious pet dogs is also reliable and practical and could potentially be used for comparative neuroscience studies ${ }^{180,181}$.

Quantitative sensory testing (QST), a method of quantifying pain, has been used to demonstrate central sensitization in human $\mathrm{OA}^{182,183}$, experimental dog $\mathrm{OA}^{184}$ and spontaneous $\operatorname{dog} \mathrm{OA}^{185}$. QST has also been used to demonstrate the efficacy of dog total hip replacements for reversing hyperalgesia ${ }^{186}$, as occurs in humans ${ }^{187}$. Dogs with spontaneous hip OA could therefore be good candidates for testing anti-hyperalgesia therapies while simultaneously experiencing the potential benefits. Overall, compelling evidence exists that veterinary randomized controlled trials (V-RCTs) in companion dogs with OA and chronic pain might reliably predict treatment efficacy in humans ${ }^{168,177,188}$. Parallel drug intervention studies are thus appropriate to accelerate therapeutic trials in dogs of drugs designed to treat pain in humans and might improve access to pain treatment not currently licensed in dogs, which could improve their welfare.

An intermediary between preclinical studies and clinical trials. Dog OA is ideally suited for V-RCTs because of the rigour of the functional outcome measures used. A study in which peak vertical force (PVF) and accelerometer data were compared to continuously track activity at home in dogs with spontaneous CCL disease showed excellent between-session reliability that aligned well with locomotor activity ${ }^{189}$. These results indicate that PVF and accelerometry are robust, reliable and reproducible non-invasive tools for monitoring and assessing the effectiveness of new therapies in spontaneous knee $\mathrm{OA}^{189}$. V-RCTs are free from the ethical objections associated with the use of experimental dog models, are aligned with the 'Three Rs' agenda ${ }^{190}$, are less expensive than using experimental dog models and increase the possibility of biological tissue sampling without using additional dogs. The approach of considering a V-RCT as an alternative intermediary when developing new therapies is highlighted by the similar clinical benefits that have been achieved when novel treatments are trialled in dogs and humans, suggesting that good clinical responses in dogs with OA undergoing treatment might also be seen in humans. Examples include treatment 


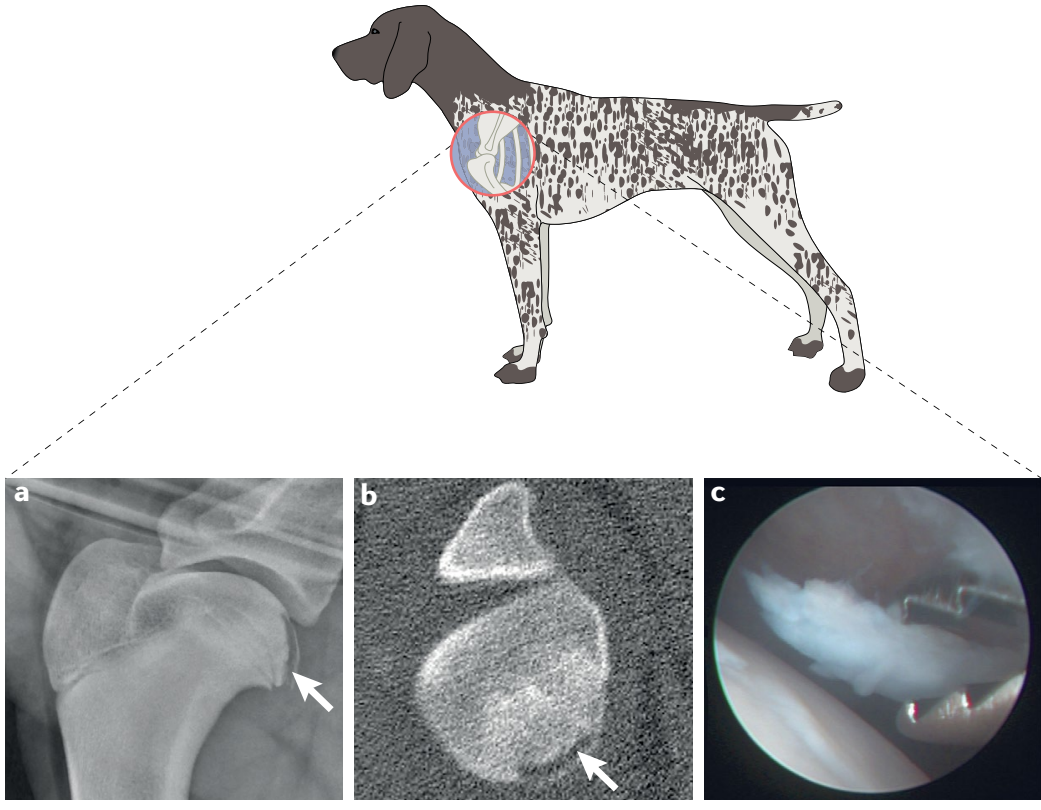

Fig. 5 | Shoulder osteochondritis dissecans in dogs. Shoulder osteochondritis dissecans lesions predominantly occur in adolescent large-breed dogs. a,b| Lateral radiograph (part a) showing a classical mineralized flap over the caudal region of the humeral head, which can also be seen in a transverse CT (part b) of the same shoulder with associated subchondral sclerosis (arrows mark the lesion). c| Osteochondritis dissecans flap being removed arthroscopically.

with anti-nerve growth factor antibodies in $\operatorname{dogs}^{177}$ and humans ${ }^{191}$ and the use of novel anti-inflammatory agents, such as resiniferatoxin and the combination of licofelone and doxycycline, which were similarly effective in dogs with spontaneous $\mathrm{OA}^{192-194}$ and in patients with OA in phase III trials ${ }^{195,196}$. Intra-articular hyaluronan injection in humans with $\mathrm{OA}^{197}$ and in dogs with $\mathrm{CHD}^{198}$ also showed comparable short-term symptomatic benefit without structure-modifying efficacy.

One example of how dog OA studies have proved useful in a One Medicine approach is in trials of stem cell therapy, which have advanced more rapidly in dogs than in humans. Allogeneic adipose tissue-derived mesenchymal stem cells harvested from visceral adipose surgical waste from ovariectomy procedures have been combined with hyaluronan and injected intra-articularly into osteoarthritic dog elbow joints, leading to reduced
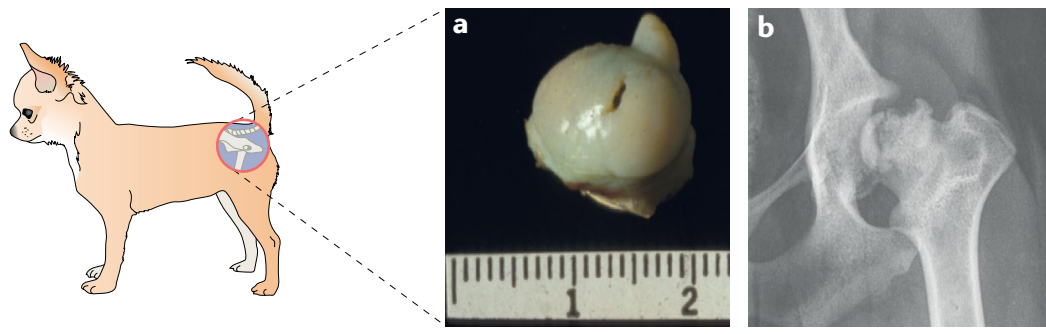

Fig. 6 | Avascular necrosis of the femoral head (Legg-Calvé-Perthes disease) in dogs. Legg-Calvé-Perthes disease (LCPD) occurs predominantly in the hip joints of small-breed dogs. a | Excised femoral head with an abnormal articular surface morphology and a central dark line indicating an articular surface defect. $\mathbf{b}$ | Ventrodorsal radiograph of a dog hip joint showing typical LCPD focal lucencies and new bone formation, as seen in advanced lesions. lameness and the regeneration of hyaline-type cartilage ${ }^{199}$. In another study, the measurement of PVF and vertical impulse using force plates showed transitory improvement in severe hip OA after intra-articular administration of adipose tissue-derived mesenchymal stem cells ${ }^{200}$.

The ability to pilot new technologies or therapies. The use of dogs with spontaneous OA for therapeutic intervention studies has several benefits, including the use of human-scale implants and instruments for procedures such as arthroscopic treatment. For example, total hip replacements have been in veterinary clinical usage since the $1970 \mathrm{~s}^{201}$. Outcomes for this intervention are good, with $<20 \%$ complication rates for cementless hip replacements after 4 years ${ }^{202}$. The development of similar implants for humans, including resurfacing hip replacements ${ }^{203}$, porous implants ${ }^{204}$ and hydroxyapatite-coated prostheses ${ }^{205}$, relied heavily on experimental testing in dogs, and current veterinary modular hip replacements include both cemented and uncemented osseointegrative replacements. In addition, similar complications are seen in dogs and humans, such as aseptic loosening, bone remodelling and implant infection.

The relatively short lifespan of a dog ( $~ 8-12$ years) also enables end-of-life retrieval studies. Post-mortem retrieval of implant material from veterinary patients is relatively inexpensive and straightforward and could provide additional insights into common surgical complications. Such samples have been used to examine the mechanical, histomorphologic and radiographic features of aseptic loosening, which is a particular concern for total hip replacements in humans under the age of 50 (REF. ${ }^{206}$ ). The results of one such study suggested that failure was initiated by poly(methyl methacrylate) de-bonding from the metal implant ${ }^{206}$. Improved implant designs, if appropriately and ethically managed, could therefore be piloted in V-RCTs in dogs, as they offer a comparatively short time frame for implant retrieval compared with a human clinical trial.

\section{Remaining challenges}

Accurately quantifying pain in animals. Pain is a cardinal symptom of OA, and symptomatic management of pain using a limited repertoire of drugs, including analgesics and anti-inflammatory agents, is central in both veterinary ${ }^{207}$ and human clinical practice ${ }^{208}$. FDA guidelines for drugs, devices and biological treatments for $\mathrm{OA}$ are available, but preclinical research advances are not yet being translated into effective new drugs in clinical practice, leading to questions regarding the predictive utility of current animal models of $\mathrm{OA}^{7,209-211}$.

Similarities in neurophysiology across mammals strongly suggest that the type of pain experienced by humans and animals is analogous ${ }^{210}$. However, pain experiences in OA are complicated and involve peripheral nociceptive sensitization, structural changes to joint innervation, central nervous system sensitization, neuropathic changes and a host of mediators, as well as simple nociceptive input from damaged joint tissues $^{212}$. Pain severity correlates poorly with radiographic structural changes in humans ${ }^{213}$ and $\operatorname{dog} s^{214}$ with OA. 
Vertical impulse

An index of limb function generated from force plate analysis and derived from the vertical vector force applied and the duration that it is imparted for.
The development of new therapies for pain in OA will therefore require effective models that recapitulate the joint changes that occur in $\mathrm{OA}$, as well as the clinical symptoms.

Levels of pain in OA are affected by synovitis, osteochondral pathology and sensitization, which are not accounted for by structural radiographic changes ${ }^{212,215}$. Good models of OA therefore need to reflect the longitudinal natural history of human OA phenotypes ${ }^{21,217}$. This premise is perhaps most elegantly demonstrated in studies of spontaneous dog OA in which advanced non-invasive imaging has revealed evidence of disease progression similar to some human OA phenotypes $^{216,217}$. Indeed, powerful, reliable and validated semi-quantitative MRI approaches have already been used in multicentre clinical trials in patients with $\mathrm{OA}^{218,219}$. The presence, number and size of bone marrow lesions (identified by characteristic MRI signal intensity changes) have been linked to the severity of pain in patients with $\mathrm{OA}^{220}$. Natural animal models for bone marrow lesions are clearly required, and indeed, bone marrow lesion-like structures with focal articular cartilage changes have been linked with disability in the dog CCL transection model of OA and in dogs with spontaneous CCL-rupture-induced $\mathrm{OA}^{221,222}$. In the search for models of human pain, researchers also need to carefully consider the evolutionary role of pain responses. As prey, rodents are thought to show less overt signs of pain than predators such as humans and dogs. As signs of pain are common end points for measuring pain, fellow predator species are likely to more accurately represent human pain physiology than rodents. Considering the important veterinary clinical desire to understand and manage pain in dogs with OA, potential exists for beneficial sharing of ideas between clinical researchers and veterinary researchers.

Reliability of veterinary data. V-RCTs clearly differ from experimental animal research; they require ethical review and incentivization, and longitudinal follow-up can be problematic. Ideally, data retrieval methods need

Table 1 | Proposed stratification of dog osteoarthritis and alignment with human disease

\begin{tabular}{|c|c|c|c|c|}
\hline OA subtype & Disease in dogs & Epidemiology in dogs & $\begin{array}{l}\text { Analogous disease } \\
\text { in humans }\end{array}$ & Epidemiology in humans \\
\hline $\begin{array}{l}\text { Acquired } \\
\text { juvenile } \\
\text { instability }\end{array}$ & $\mathrm{CHD}$ & $\begin{array}{l}\text { - Occurs in dogs from large and/or giant } \\
\text { breeds (prevalent in Golden Retrievers, } \\
\text { Labrador Retrievers, Rottweilers and } \\
\text { German Shepherds; extremely rare in } \\
\text { Greyhounds and Borzois) that are } \\
\text { 3-12 months old } \\
\text { - Progression to OA in } 1 \text { year }\end{array}$ & DDH & $\begin{array}{l}\text { - Occurs in infants } \\
\text { - Prevalent in females } \\
\text { - Progression to OA in } 30 \text { years }\end{array}$ \\
\hline $\begin{array}{l}\text { Acquired adult } \\
\text { instability }\end{array}$ & $\begin{array}{l}\mathrm{CCL} \text { rupture and } \\
\text { meniscal injuries }\end{array}$ & $\begin{array}{l}\text { - Occurs in young adult dogs from } \\
\text { medium or large breeds (Rottweilers, } \\
\text { Golden Retrievers, Labrador Retrievers } \\
\text { and Staffordshire Bull Terriers) that are } \\
\text { commonly }>2 \text { years old or in dogs from } \\
\text { small breeds (Yorkshire Terriers and West } \\
\text { Highland White Terriers) that are }>6 \text { years } \\
\text { old } \\
\text { - 50\% of dogs develop contralateral } \\
\text { disease within } 2 \text { years } \\
\text { - } 50 \% \text { of dogs have meniscal (mostly } \\
\text { medial) pathology } \\
\text { - Increased risk in neutered females }\end{array}$ & $\begin{array}{l}\text { ACL rupture and } \\
\text { meniscal injuries }\end{array}$ & $\begin{array}{l}\text { - Occurs in active adults, commonly during } \\
\text { sporting activities } \\
\text { - Influenced by the menstrual cycle }\end{array}$ \\
\hline $\begin{array}{l}\text { Developmental } \\
\text { vascular }\end{array}$ & LCPD & $\begin{array}{l}\text { - Occurs in dogs from small breeds (toy } \\
\text { dogs and Terriers) that are 4-11 months } \\
\text { old and has no sex predilection } \\
\text { - Autosomal recessive trait in Miniature } \\
\text { Poodles and West Highland White } \\
\text { Terriers }\end{array}$ & $\begin{array}{l}\text { - LCPD } \\
\text { - Adolescent ANFH }\end{array}$ & $\begin{array}{l}\text { - LCPD occurs in children between } 4 \text { and } \\
8 \text { years old and is more prevalent in boys } \\
\text { than girls } \\
\text { - Adolescent ANFH occurs in adolescents } \\
\text { near skeletal maturity and is associated } \\
\text { with low circulating concentrations of } \\
\text { IGF1 and poor caliber arteries }\end{array}$ \\
\hline $\begin{array}{l}\text { Developmental } \\
\text { endochondral }\end{array}$ & $\begin{array}{l}\text { Osteochondritis } \\
\text { dissecans of the } \\
\text { shoulder or knee }\end{array}$ & $\begin{array}{l}\text { - Occurs in dogs from large or giant breeds } \\
\text { (Great Danes, Labrador Retrievers and } \\
\text { Border Collies) that are } 5-18 \text { months old } \\
\text { - More prevalent in males and often } \\
\text { bilateral }\end{array}$ & $\begin{array}{l}\text { Osteochondritis } \\
\text { dissecans }\end{array}$ & $\begin{array}{l}\text { - Occurs in children, adolescents and } \\
\text { young adults } \\
\text { - Family history } \\
\text { - More prevalent in males and often } \\
\text { bilateral }\end{array}$ \\
\hline $\begin{array}{l}\text { Environmental: } \\
\text { obesity-related }\end{array}$ & $\begin{array}{l}\text { OA of the elbow, } \\
\text { hip or shoulder }\end{array}$ & $\begin{array}{l}\text { Can occur in any breed, often between } \\
4 \text { and } 8 \text { years of age }\end{array}$ & $\begin{array}{l}\text { OA of the knee and } \\
\text { small joints of the } \\
\text { hands }\end{array}$ & $\begin{array}{l}\text { Occurs in middle-aged and older adults; } \\
\text { multiple joints are often affected }\end{array}$ \\
\hline $\begin{array}{l}\text { Environmental: } \\
\text { trauma-related }\end{array}$ & $\begin{array}{l}\text { OA of the hip, } \\
\text { elbow, hock } \\
\text { (ankle), carpus } \\
\text { or digits }\end{array}$ & $\begin{array}{l}\text { Occurs in racing Greyhounds that are } \\
4-8 \text { years old as digital OA and carpal } \\
\text { sprains that lead to OA }\end{array}$ & $\begin{array}{l}\text { Physical } \\
\text { occupation- } \\
\text { associated OA }\end{array}$ & $\begin{array}{l}\text { Occurs in athletic individuals, often in } \\
\text { middle age }\end{array}$ \\
\hline
\end{tabular}

$\mathrm{ACL}$, anterior cruciate ligament; $\mathrm{ANFH}$, avascular necrosis of the femoral head; $\mathrm{CCL}$, cranial cruciate ligament; $\mathrm{CHD}$, canine hip dysplasia; DDH, developmental dysplasia of the hip; IGF1, insulin-like growth factor 1; LCPD, Legg-Calvé-Perthes disease; OA, osteoarthritis. ${ }^{2}$ The potential exists to classify an adult form of CHD (with acetabular dysplasia) in which late-onset hip OA occurs in aged dogs that are otherwise normal upon screening at 2 years of age. 
to be non-invasive, non-harming and in line with clinical management, such as walking upon a pressure walkway or owner-assessed metrics. Non-invasive imaging, such as MRI, CT and arthroscopic imaging, can be highly informative, but its use is often limited by cost and the need to show a clinical indication. Excellent V-RCTs are possible but require careful planning ${ }^{223}$.

A further issue is the throughput of veterinary studies; a disease might be common, but unlike many human health-care providers such as the National Health Service (NHS) in the UK, the veterinary profession has historically been composed of many independent veterinarians, each of whom see a relatively small number of animals with a particular condition. However, the growth of multi-practice corporate ownership might promote uniformity in veterinary clinical approaches and increase the number of animals available for a study. Initiatives such as the UK National Veterinary Canine Hip Replacement Registry ${ }^{224}$ and the Comparative Oncology Trials Consortium ${ }^{10}$ are also seeking to improve the acquisition of animals with particular diseases, and more standardized clinical outcome assessments are slowly being adopted across veterinary groups $^{225}$. As with human trials, loss to follow-up and mid-trial exclusions also make obtaining suitable numbers of patients for analysis challenging. The lack of any centralized funding is also an issue, and veterinary medical care is essentially privately funded, which complicates the development of new therapies or research avenues. Research is currently further hampered by the fact that funding bodies often want results in a 1-2-year time frame, which is not feasible for OA outcome assessment.

Moreover, scepticism seems to exist concerning the variability in noisy veterinary clinical data, compared with data from animal models that have controllable genetic backgrounds but poorly defined disease processes. Such attitudes ignore the fact that veterinary clinical studies conveniently mirror the noise encountered in human trials. Even when conducted well, it can be difficult to acquire good quality veterinary research published in high impact journals (perhaps partly owing to lack of aspiration from the authors), which can slow the dissemination of research; the inclusion of veterinarians on scientific review boards could be advantageous to alter this trend. Despite these issues, a great deal of potential and opportunity exist to develop veterinary research that could be highly informative and could offer different advantages to animal model research and human clinical trials.

\section{Conclusions}

In this Review, we have sought to highlight the potential benefits for dog and human health that could follow the adoption of One Medicine approaches to basic and clinical research and practice for OA. Human and dog $\mathrm{OA}$ are heterogeneous and spontaneous, and we have emphasized some analogous forms of OA in which the dog is potentially the best model for the human counterpart and have also highlighted some homologies that underpin OA disease mechanisms, similar comorbidities and known distinctions. Much can be gained from studying a large animal with spontaneous $\mathrm{OA}$, and understanding the reasons behind any differences will be just as informative as understanding the similarities.

We have consequently also sought to increase awareness of V-RCTs (a database is currently being developed by the American Veterinary Medical Association), national repositories of $\operatorname{dog} \mathrm{OA}$ tissue samples, national retrieval banks for implants and V-RCT guidelines (including standardized outcome assessments to enable their amalgamation into an OA One Medicine paradigm). These resources have barely been exploited, and their integration into research using a One Medicine approach could generate breakthroughs in OA treatment in dogs and humans and in understanding how genetics, epigenetics, biomechanics and lifestyle affect $\mathrm{OA}$ aetiology and pathogenesis.

Published online 5 April 2019
1. Murphy, L. \& Helmick, C. G. The impact of osteoarthritis in the United States: a population-health perspective: a population-based review of the fourth most common cause of hospitalization in U.S. adults. Orthop. Nurs. 31, 85-91 (2012).

2. March, L. et al. Osteoarthritis: a serious disease. OARSI.org https://www.oarsi.org/sites/default/files/ docs/2016/oarsi_white_paper_oa_serious_ disease_121416_1.pdf (2016).

3. Little, C. B. \& Zaki, S. What constitutes an 'animal model of osteoarthritis' - the need for consensus? Osteoarthritis Cartilage 20, 261-267 (2012).

4. Pond, M. J. \& Nuki, G. Experimentally-induced osteoarthritis in the dog. Ann. Rheum. Dis. 32, 387-388 (1973).

5. Stockwell, R. A., Billingham, M. E. \& Muir, H. Ultrastructural changes in articular cartilage after experimental section of the anterior cruciate ligament of the dog knee. J. Anat. 136, 425-439 (1983).

6. Moskowitz, R. W. et al. Experimentally induced degenerative joint lesions following partial meniscectomy in the rabbit. Arthritis Rheum. 16, 397-405 (1973)

7. Malfait, A.-M. \& Little, C. B. On the predictive utility of animal models of osteoarthritis. Arthritis Res. Ther 17, 225 (2015).

8. Vincent, T. L. et al. Mapping pathogenesis of arthritis through small animal models. Rheumatology $\mathbf{5 1}$, 1931-1941 (2012).
9. $\mathrm{Li}, \mathrm{N}$. et al. A novel p.Gly630Ser mutation of $\mathrm{COL} 2 \mathrm{~A} 1$ in a Chinese family with presentations of Legg-CalvéPerthes disease or avascular necrosis of the femora head. PLOS ONE 9, e 100505 (2014).

10. Kol, A et al. Companion animals: translational scientist's new best friends. Sci. Transl Med. 7 , 308ps21 (2015).

11. Bendele, A. M. Animal models of osteoarthritis. J. Musculoskelet. Neuronal Interact. 1, 363-376 (2001).

12. Anderson, K. L. et al. Prevalence, duration and risk factors for appendicular osteoarthritis in a UK dog population under primary veterinary care. Sci. Rep. 8 5641 (2018).

13. Johnston, S. A Osteoarthritis. Joint anatomy, physiology, and pathobiology. Vet. Clin. North Am Small Anim. Pract. 27, 699-723 (1997).

14. Innes, J. F., Barr, A. R. \& Sharif, M. Efficacy of oral calcium pentosan polysulphate for the treatment of osteoarthritis of the canine stifle joint secondary to cranial cruciate ligament deficiency. Vet. Rec. 146 , 433-437 (2000)

15. Mehler, S. J., May, L. R., King, C., Harris, W. S. \& Shah, Z. A prospective, randomized, double blind placebo-controlled evaluation of the effects of eicosapentaenoic acid and docosahexaenoic acid on the clinical signs and erythrocyte membrane polyunsaturated fatty acid concentrations in dogs with osteoarthritis. Prostaglandins Leukot. Essent. Fatty Acids 109, 1-7 (2016).
16. Gregory, M. H. et al. A review of translational animal models for knee osteoarthritis. Arthritis 2012 , 764621 (2012).

17. Liu, W. et al. Spontaneous and experimental osteoarthritis in dog: similarities and differences in proteoglycan levels. J. Orthop. Res. 21, 730-737 (2003).

18. Page, A. E. et al. Determination of loading parameters in the canine hip in vivo. J. Biomech. 26, 571-579 (1993).

19. Pearson-Ceol, J. Literature review on the effects of obesity on knee osteoarthritis. Orthop. Nurs. 26, 289-292 (2007).

20. Lauten, S. D. Nutritional risks to large-breed dogs: from weaning to the geriatric years. Vet. Clin. North Am. Small Anim Pract 36, 1345-1359 (2006).

21. Smith, G. K. et al. Lifelong diet restriction and radiographic evidence of osteoarthritis of the hip joint in dogs. J. Am. Vet. Med. Assoc. 229, 690-693 (2006)

22. Kealy, R. D. et al. Five-year longitudinal study on limited food consumption and development of osteoarthritis in coxofemoral joints of dogs. J. Am. Vet. Med. Assoc. 210, 222-225 (1997).

23. Newman, R. G. et al. The effects of lifetime food restriction on the development of osteoarthritis in the canine shoulder. Vet. Surg. 37, 102-107 (2008).

24. Huck, J. L. et al. A longitudinal study of the influence of lifetime food restriction on development of osteoarthritis in the canine elbow. Vet. Surg. 38 , 192-198 (2009). 
25. Yusuf, E. et al. Association between weight or body mass index and hand osteoarthritis: a systematic review. Ann. Rheum. Dis. 69, 761-765 (2009)

26. Francisco, V. et al. Biomechanics, obesity, and osteoarthritis. The role of adipokines: when the levee breaks. J. Orthop. Res. 23, 1233 (2017).

27. Ryan, V. H. et al. Adipokine expression and secretion by canine adipocytes: stimulation of inflammatory adipokine production by LPS and TNFa. Pflugers Arch 460, 603-616 (2010).

28. Lane, N. E. et al. Association of mild acetabular dysplasia with an increased risk of incident hip osteoarthritis in elderly white women: the study of osteoporotic fractures. Arthritis Rheum. 43, 400-404 (2000).

29. Thomas, G. E. R. et al. Subclinical deformities of the hip are significant predictors of radiographic osteoarthritis and joint replacement in women. A 20 year longitudinal cohort study. Osteoarthritis Cartilage 22, 1504-1510 (2014).

30. Cachon, T. et al. Risk of simultaneous phenotypic expression of hip and elbow dysplasia in dogs. vet. Comp. Orthop. Traumatol. 23, 28-30 (2009).

31. Rhodes, A. M. L. \& Clarke, N. M. P. A review of environmental factors implicated in human developmental dysplasia of the hip. J. Child Orthop. 8, 375-379 (2014)

32. Jacobsen, S. Adult hip dysplasia and osteoarthritis. Studies in radiology and clinical epidemiology. Acta Orthop. Suppl. 77, 1-37 (2006).

33. Baker-LePain, J. C. \& Lane, N. E. Relationship between joint shape and the development of osteoarthritis. Curr. Opin. Rheumatol. 22, 538-543 (2010)

34. Weinstein, S. L. Natural history of congenital hip dislocation (CDH) and hip dysplasia. Clin. Orthop. Relat. Res. 225, 62-76 (1987).

35. Pascual-Garrido, C. et al. Canine hip dysplasia: a natural animal model for human developmental dysplasia of the hip. J. Orthop. Res. 36, 1807-1817 (2017).

36. Todhunter, R. J. et al. Evaluation of multiple radiographic predictors of cartilage lesions in the hip joints of eight-month-old dogs. Am. J. Vet. Res. 64, 1472-1478 (2003)

37. Jacobsen, S. ¿ Sonne-Holm, S. Hip dysplasia: a significant risk factor for the development of hip osteoarthritis. A cross-sectional survey. Rheumatology 44, 211-218 (2005)

38. Todhunter, R. J. et al. Onset of epiphyseal mineralization and growth plate closure in radiographically normal and dysplastic Labrador Retrievers. J. Am. Vet. Med. Assoc. 210, 1458-1462 (1997).

39. Greisen, H. A., Summers, B. A. \& Lust, C. Ultrastructure of the articular cartilage and synovium in the early stages of degenerative joint disease in canine hip joints. Am. J. Vet. Res. 43, 1963-1971 (1982).

40. Feng, W. J., Wang, H., Shen, C., Zhu, J. F. \& Chen, X. D. Severe cartilage degeneration in patients with developmental dysplasia of the hip. IUBMB Life 69, 179-187 (2017)

41. Loder, R. T. \& Todhunter, R. J. The demographics of canine hip dysplasia in the United States and Canada. J. Vet. Med. 2017, 5723476 (2017).

42. Smith, G. K. et al. Chronology of hip dysplasia development in a cohort of 48 Labrador Retrievers followed for life. Vet. Surg. 41, 20-33 (2012).

43. Ganz, R. et al. Femoroacetabular impingement: a cause for osteoarthritis of the hip. Clin. Orthop. Relat. Res. 417, 112-120 (2003)

44. Kotlarsky, P., Haber, R., Bialik, V. \& Eidelman, M. Developmental dysplasia of the hip: what has changed in the last 20 years? World J. Orthop. 6, 886-901 (2015).

45. Pollet, V., Percy, V. \& Prior, H. J. Relative risk and incidence for developmental dysplasia of the hip. J. Pediatr. 181, 202-207 (2017).

46. de Hundt, M. et al. Risk factors for developmental dysplasia of the hip: a meta-analysis. Eur. J. Obstet. Gynecol. Reprod. Biol. 165, 8-17 (2012).

47. Li, L. et al. Heritability and sibling recurrent risk of developmental dysplasia of the hip in Chinese population. Eur. J. Clin. Invest. 43, 589-594 (2013).

48. Feldman, G. J. et al. Variable expression and incomplete penetrance of developmental dysplasia of the hip: clinical challenge in a 71-member multigeneration family. J. Arthroplasty 27, 527-532 (2012).

49. Hogervorst, T., Eilander, W., Fikkers, J. T. \& Meulenbelt, I. Hip ontogenesis: how evolution, genes, and load history shape hip morphotype and cartilotype. Clin. Orthop. Relat. Res. 470. 3284-3296 (2012)
50. Kaneene, J. B., Mostosky, U. V. \& Miller, R. Update of a retrospective cohort study of changes in hip joint phenotype of dogs evaluated by the OFA in the United States, 1989-2003. Vet. Surg. 38, 398-405 (2009).

51. Breur, G. J., Lambrecht, N. E. \& Todhunter, R. J. in The Genetics of the Dog 2nd edn (eds Ostrander, E. A \& Ruvinsky, A.) 136-153 (CABI Publishing, 2012).

52. Hayward, J. J. et al. Complex disease and phenotype mapping in the domestic dog. Nat. Commun. 7 , 10460 (2016)

53. Huang, M. et al. A novel iterative mixed model to remap three complex orthopedic traits in dogs. PLOS ONE 12, e0176932 (2017).

54. Bartolomé, N. et al. A genetic predictive model for canine hip dysplasia: integration of genome wide association study (GWAS) and candidate gene approaches. PLOS ONE 10, e0122558 (2015).

55. Sánchez-Molano, E. et al. Quantitative trait loci mapping for canine hip dysplasia and its related traits in UK Labrador Retrievers. BMC Genomics 15, 833 (2014).

56. Fels, L. \& Distl, O. Identification and validation of quantitative trait loci (QTL) for canine hip dysplasia (CHD) in German Shepherd dogs. PLoS ONE 9 e96618 (2014).

57. Kadri, N. K., Guldbrandtsen, B., Sørensen, P. \& Sahana, G. Comparison of genome-wide association methods in analyses of admixed populations with complex familial relationships. PLOS ONE 9, e88926 (2014).

58. Lavrijsen, I. C. et al. Genome wide analysis indicates genes for basement membrane and cartilage matrix proteins as candidates for hip dysplasia in Labrador Retrievers. PLOS ONE 9, e87735 (2014)

59. Pfahler, S. \& Distl, O. Identification of quantitative trait loci (QTL) for canine hip dysplasia and canine elbow dysplasia in Bernese Mountain Dogs. PLoS ONE 7. e49782 (2012).

60. Zhou, Z. et al. Differential genetic regulation of canine hip dysplasia and osteoarthritis. PLOS ONE 5, e13219 (2010).

61. Todhunter, R. J. Gene expression in hip soft tissues in incipient canine hip dysplasia and osteoarthritis. J. Orthop. Res. 37, 313-324 (2019).

62. Feldman, G. J. et al. Developmental dysplasia of the hip: linkage mapping and whole exome sequencing identify a shared variant in CX3CR1 in all affected members of a large multigeneration family. J. Bone Miner. Res. 28, 2540-2549 (2013).

63. Feldman, G. J., Parvizi, J., Sawan, H., Erickson, J. A $\&$ Peters, C. L. Linkage mapping and whole exome sequencing identify a shared variant in CX3CR 1 in a large multi-generation family. J. Arthroplasty 29, 238-241 (2014).

64. Li, L. et al. CX3CR1 polymorphisms associated with an increased risk of developmental dysplasia of the hip in human. J. Orthop. Res. 35, 377-380 (2017).

65. Xiao, Y. et al. Macrophages and osteoclasts stem from a bipotent progenitor downstream of a macrophage/ osteoclast/dendritic cell progenitor. Blood Adv. 1, 1993-2006 (2017).

66. Feldman, G., Offemaria, A Sawan, H., Parvizi, J. \& Freeman, T. A. A murine model for developmental dysplasia of the hip: ablation of CX3CR1 affects acetabular morphology and gait. J. Transl Med. 15 , 233 (2017).

67. Hatzikotoulas, K. et al. Genome-wide association study of developmental dysplasia of the hip identifies an association with GDF5. Commun. Biol. 1, 56 (2018).

68. Beals, R. K. Familial primary acetabular dysplasia and dislocation of the hip. Clin. Orthop. Relat. Res. 406 , 109-115 (2003).

69. Sandell, L. J. Etiology of osteoarthritis: genetics and synovial joint development. Nat. Rev. Rheumatol. 8 , 77-89 (2012)

70. Friedenberg, S. G. et al. Evaluation of a fibrillin 2 gene haplotype associated with hip dysplasia and incipient osteoarthritis in dogs. Am. J. Vet. Res. 72, 530-540 (2011).

71. Sadee, W. et al. Missing heritability of common diseases and treatments outside the protein-coding exome. Hum. Genet. 133, 1199-1215 (2014).

72. Lust, G. et al. Joint laxity and its association with hip dysplasia in Labrador Retrievers. Am. J. Vet. Res. 54, 1990-1999 (1993).

73. Runge, J. J., Kelly, S. P., Gregor, T. P., Kotwal, S. \& Smith, G. K. Distraction index as a risk factor for osteoarthritis associated with hip dysplasia in four large dog breeds. J. Small Anim. Pract. 51, 264-269 (2010).

74. Giorgi, M., Carriero, A., Shefelbine, S. J. \& Nowlan, N. C. Effects of normal and abnormal loading conditions on morphogenesis of the prenatal hip joint: application to hip dysplasia. J. Biomech 48 , 3390-3397 (2015).

75. de Rooster, H., de Bruin, T. \& Van Bree, H. Morphologic and functional features of the canine cruciate ligaments. Vet. Surg. 35, 769-780 (2006).

76. Bozynski, C. et al. Evaluation of partial transection versus synovial debridement of the $A C L$ as novel canine models for management of ACL injuries. J. Knee Surg. 28, 404-410 (2015).

77. Lahm, A. et al. An experimental canine model for subchondral lesions of the knee joint. Knee 12, 51-55 (2005).

78. Panula, H. E., Helminen, H. J. \& Kiviranta, I. Slowly progressive osteoarthritis after tibial valgus osteotomy in young beagle dogs. Clin. Orthop. Relat. Res. 343 192-202 (1997).

79. Frost-Christensen, L. N. et al. Degeneration, inflammation, regeneration, and pain/disability in dogs following destabilization or articular cartilage grooving of the stifle joint. Osteoarthritis Cartilage 16 1327-1335 (2008).

80. Simon, D. et al. The relationship between anterior cruciate ligament injury and osteoarthritis of the knee. Adv. Orthop. 2015, 1-11 (2015)

81. Innes, J. F., Costello, M., Barr, F. J., Rudorf, H. \& Barr, A. R. S. Radiographic progression of osteoarthritis of the canine stifle joint: a prospective study. Vet. Radiol. Ultrasound 45, 143-148 (2004)

82. Comerford, E. J. et al. Update on the aetiopathogenesis of canine cranial cruciate ligament disease. Vet. Comp. Orthop. Traumatol. 24, 91-98 (2011).

83. Taylor-Brown, F. E. et al. Epidemiology of cranial cruciate ligament disease diagnosis in dogs attending primary-care veterinary practices in England. Vet. Surg. 44, 777-783 (2015).

84. Pritzker, K. P. Animal models for osteoarthritis: processes, problems and prospects. Ann. Rheum. Dis. 53, 406-420 (2004)

85. Wilke, V. L. et al. Inheritance of rupture of the cranial cruciate ligament in Newfoundlands. J. Am. Vet. Med. Assoc. 228, 61-64 (2006).

86. Buote, N., Fusco, J. \& Radasch, R. Age, tibial plateau angle, sex, and weight as risk factors for contralateral rupture of the cranial cruciate ligament in Labradors. Vet. Surg. 38, 481-489 (2009).

87. Cook, J. L. Cranial cruciate ligament disease in dogs: biology versus biomechanics. Vet. Surg. 39, 270-277 (2010).

88. Blanke, F. et al. Risk of noncontact anterior cruciate ligament injuries is not associated with slope and concavity of the tibial plateau in recreational alpine skiers: a magnetic resonance imaging-based case-control study of 121 patients. Am. J. Sports Med. 44, 1508-1514 (2016).

89. Trompeter, A. J., Gill, K., Appleton, M. A. C. \& Palmer, S. H. Predicting anterior cruciate ligament integrity in patients with osteoarthritis. Knee Surg. Sports Traumatol. Arthrosc. 17, 595-599 (2009).

90. Lohmander, L. S., Englund, P. M., Dahl, L. L. \& Roos, E. M. The long-term consequence of anterior cruciate ligament and meniscus injuries. Am. J. Sports Med. 35, 1756-1769 (2017).

91. Joseph, A. M. et al. A multisport epidemiologic comparison of anterior cruciate ligament injuries in high school athletics. J. Athl. Train. 48, 810-817 (2013).

92. Flynn, R. K. et al. The familial predisposition toward tearing the anterior cruciate ligament: a case control study. Am. J. Sports Med. 33, 23-28 (2005).

93. Trojian, T. H. \& Collins, S. The anterior cruciate ligament tear rate varies by race in professional women's basketball. Am. J. Sports Med. 34 , 895-898 (2006).

94. O'Connell, K. et al. Interactions between collagen gene variants and risk of anterior cruciate ligament rupture. Eur. J. Sport Sci. 15, 341-350 (2015).

95. Khoury, L. E. et al. ELN and FBN2 gene variants as risk factors for two sports-related musculoskeletal injuries. Int. J. Sports Med. 36, 333-337 (2015)

96. Rahim, M. et al. The association of genes involved in the angiogenesis-associated signaling pathway with risk of anterior cruciate ligament rupture. J. Orthop. Res. 32, 1612-1618 (2014)

97. Stepien-Słodkowska, M. et al. The $+1245 \mathrm{~g} / \mathrm{t}$ polymorphisms in the collagen type I alpha 1 (col1a1) gene in polish skiers with anterior cruciate ligament injury. Biol. Sport 30, 57-60 (2013).

98. Posthumus, M. et al. Genetic risk factors for anterior cruciate ligament ruptures: $\mathrm{COL} 1 \mathrm{~A} 1$ gene variant. Br. J. Sports Med. 43, 352-356 (2009). 
99. Mannion, S. et al. Genes encoding proteoglycans are associated with the risk of anterior cruciate ligament ruptures. Br. J. Sports Med. 48, 1640-1646 (2014)

100. Kim, S. K. et al. Genome-wide association screens for Achilles tendon and ACL tears and tendinopathy. PLOS ONE 12, e0170422 (2017).

101. Kaynak, M., Nijman, F., van Meurs, J., Reijman, M. \& Meuffels, D. E. Genetic variants and anterior cruciate ligament rupture: a systematic review. Sports Med. 47, 1637-1650 (2017)

102. Khoschnau, S. et al. Type I collagen alpha1 Sp1 polymorphism and the risk of cruciate ligament ruptures or shoulder dislocations. Am. J. Sports Med. 36, 2432-2436 (2008)

103. Posthumus, M., September, A. V., Schwellnus, M. P. $\&$ Collins, M. Investigation of the Sp 1-binding site polymorphism within the COL1A1 gene in participants with Achilles tendon injuries and controls. J. Sci. Med. Sport 12, 184-189 (2009).

104. Ficek, K. et al. Gene variants within the COL1A1 gene are associated with reduced anterior cruciate ligamen injury in professional soccer players. J. Sci. Med. Sport 16, 396-400 (2013)

105. Wilke, V. L., Zhang, S., Evans, R. B., Conzemius, M. G. $\&$ Rothschild, M. F. Identification of chromosomal regions associated with cranial cruciate ligament rupture in a population of Newfoundlands. Am. J. Vet. Res. 70, 1013-1017 (2009)

106. Baird, A. E. G., Carter, S. D., Innes, J. F., Ollier, W. \& Short, A. Genome-wide association study identifies genomic regions of association for cruciate ligament rupture in Newfoundland dogs. Anim. Genet. 45 542-549 (2014).

107. Baird, A. E. G., Carter, S. D., Innes, J. F., Ollier, W. E. \& Short, A. D. Genetic basis of cranial cruciate ligament rupture (CCLR) in dogs. Connect. Tissue Res. 55, 275-281 (2014).

108. Baker, L. A. et al. Genome-wide association analysis in dogs implicates 99 loci as risk variants for anterior cruciate ligament rupture. PLOS ONE 12, e0173810 (2017)

109. Brandt, K. D. et al. Anterior (cranial) cruciate ligament transection in the dog: a bona fide model of osteoarthritis, not merely of cartilage injury and repair. J. Rheumatol. 18, 436-446 (1991).

110. Innes, J. F., Bacon, D., Lynch, C. \& Pollard, A Long-term outcome of surgery for dogs with cranial cruciate ligament deficiency. Vet. Rec. 147, 325-328 (2000).

111. Bleedorn, J. A. et al. Synovitis in dogs with stable stifle joints and incipient cranial cruciate ligament rupture: a cross-sectional study. Vet. Surg. 40, 531-543 (2011)

112. Little, J. P. et al. Arthroscopic assessment of stifle synovitis in dogs with cranial cruciate ligament rupture. PLoS ONE 9, e97329 (2014).

113. Muir, P. et al. Lymphocyte populations in joint tissues from dogs with inflammatory stifle arthritis and associated degenerative cranial cruciate ligament rupture. Vet. Surg. 40, 753-761 (2011).

114. Kraus, V. B. et al. Direct in vivo evidence of activated macrophages in human osteoarthritis. Osteoarthritis Cartilage 24, 1613-1621 (2016).

115. Yarnall, B. et al. Synovial macrophage polarization in dogs with degenerative cranial cruciate ligament rupture [abstract]. Vet. Surg. 46, E1-E75 (2017)

116. de Bruin, T., de Rooster, H., Van Bree, H., Duchateau, L. $\Sigma$ Cox, E. Cytokine mRNA expression in synovial fluid of affected and contralateral stifle joints and the left shoulder joint in dogs with unilateral disease of the stifle joint. Am. J. Vet. Res. 68, 953-961 (2007).

117. Sample, S. J. et al. Radiographic and magnetic resonance imaging predicts severity of cruciate ligament fiber damage and synovitis in dogs with cranial cruciate ligament rupture. PLOS ONE 12, e0178086 (2017).

118. Faryniarz, D. A., Bhargava, M., Lajam, C., Attia, E. T. \& Hannafin, J. A. Quantitation of estrogen receptors and relaxin binding in human anterior cruciate ligament fibroblasts. In Vitro Cell. Dev. Biol. Anim. 42 176-181 (2006)

119. Liu, S. H., Al-Shaikh, R. A., Panossian, V., Finerman, G. A \& Lane, J. M. Estrogen affects the cellular metabolism of the anterior cruciate ligament. A potential explanation for female athletic injury. Am. $J$. Sports Med. 25, 704-709 (1997).

120. Slauterbeck, J. R. et al. The menstrual cycle, sex hormones, and anterior cruciate ligament injury. J. Athl. Train. 37, 275-278 (2002)

121. Slauterbeck, J. R., Pankratz, K., Xu, K. T., Bozeman, S. C. $\&$ Hardy, D. M. Canine ovariohysterectomy and orchiectomy increases the prevalence of $\mathrm{ACL}$ injury. Clin. Orthop. Relat. Res. 429, 301-305 (2004).
122. McGreevy, P. D. et al. Prevalence of obesity in dogs examined by Australian veterinary practices and the risk factors involved. Vet. Rec. 156, 695-702 (2005)

123. Linn, S., Murtaugh, B. \& Casey, E. Role of sex hormones in the development of osteoarthritis. PMR 4, S169-S173 (2012).

124. Demko, J. \& Mclaughlin, R. Developmental orthopedic disease. Vet. Clin. North Am. Small Anim. Pract. 35 , 1111-1135 (2005)

125. Bohndorf, K. Osteochondritis (osteochondrosis) dissecans: a review and new MRI classification. Eur. Radiol. 8, 103-112 (1998).

126. Schenck, R. C. \& Goodnight, J. M. Osteochondritis dissecans. J. Bone Joint Surg. Am. 78, 439-456 (1996).

127. Yonetani, Y. et al. Histological evaluation of juvenile osteochondritis dissecans of the knee: a case series. Knee Surg. Sports Traumatol. Arthrosc. 18, 723-730 (2010).

128. Leighton, R. L. Historical perspectives of osteochondrosis. Vet. Clin. North Am. Small Anim. Pract. 28, 1-16 (1998)

129. Wall, E. \& Stein, Von, D. Juvenile osteochondritis dissecans. Orthop. Clin. North Am. 34, 341-353 (2003).

130. Jans, L. B. O., Jaremko, J. L., Ditchfield, M. \& Verstraete, K. L. Evolution of femoral condylar ossification at MR imaging: frequency and patient age distribution. Radiology 258, 880-888 (2011).

131. Olivieri, M. et al. Arthroscopic treatment of osteochondritis dissecans of the shoulder in 126 dogs. Vet. Comp. Orthop. Traumatol. 20, 65-69 (2007).

132. Fitzpatrick, N., Van Terheijden, C., Yeadon, R. \& Smith, T. J. Osteochondral autograft transfer for treatment of osteochondritis dissecans of the caudocentral humeral head in dogs. Vet. Surg. 39 925-935 (2010)

133. Staines, K. A. et al. Endochondral growth defect and deployment of transient chondrocyte behaviors underlie osteoarthritis onset in a natural murine model. Arthritis Rheumatol. 68, 880-891 (2016).

134. Fuerst, M. et al. Calcification of articular cartilage in human osteoarthritis. Arthritis Rheum. 60 2694-2703 (2009).

135. Teunissen, M. et al. Growth plate expression profiling large and small breed dogs provide new insights in endochondral bone formation. J. Orthop. Res. 211 109 (2017).

136. Rawlinson, S. C. F. et al. Genetic selection for fast growth generates bone architecture characterised by enhanced periosteal expansion and limited consolidation of the cortices but a diminution in the early responses to mechanical loading. Bone $\mathbf{4 5}$, 357-366 (2009).

137. Pitsillides, A. A., Rawlinson, S. C., Mosley, J. R. \& Lanyon, L. E. Bone's early responses to mechanica loading differ in distinct genetic strains of chick: selection for enhanced growth reduces skeletal adaptability. J. Bone Miner. Res. 14, 980-987 (1999)

138. Chaudhry, S., Phillips, D. \& Feldman, D. Legg-CalvêPerthes disease: an overview with recent literature. Bull. Hosp. Jt Dis. (2013) 72, 18-27 (2014).

139. Wynne-Davies, R. Acetabular dysplasia and familial joint laxity: two etiological factors in congenital dislocation of the hip. A review of 589 patients and their families. J. Bone Joint Surg. Br. 52, 704-716 (1970).

140. Wiig, O., Terjesen, T., Svenningsen, S. \& Lie, S. A. The epidemiology and aetiology of Perthes' disease in Norway. A nationwide study of 425 patients. J. Bone Joint Surg. Br. 88, 1217-1223 (2006)

141. Hall, D. J. Genetic aspects of Perthes' disease. A critical review. Clin. Orthop. Relat. Res. 209, 100-114 (1986)

142. Perry, D. C. et al. Perthes' disease: deprivation and decline. Arch. Dis. Child. 96, 1124-1128 (2011).

143. Vasseur, P. B., Foley, P., Stevenson, S. \& Heitter, D. Mode of inheritance of Perthes' disease in Manchester terriers. Clin Orthop. Relat Res 244, 281-292 (1989).

144. LaFond, E., Breur, G. J. \& Austin, C. C. Breed susceptibility for developmental orthopedic diseases in dogs. J. Am. Anim. Hosp. Assoc. 38, 467-477 (2002).

145. Starr-Moss, A. N., Nowend, K. L, Alling, K. M. Zepp, E. J. \& Murphy, K. E. Exclusion of COL2A1 in canine Legg-Calvê-Perthes disease. Anim. Genet. 43, $112-113$ (2012).

146. Srzentic', S. et al. Predictive genetic markers of coagulation, inflammation and apoptosis in Perthes disease-Serbian experience. Eur. J. Pediatr. 174 1085-1092 (2015)

147. Zheng, P., Yang, T., Ju, L., Jiang, B. \& Lou, Y. Epigenetics in Legg-Calvê-Perthes disease: a study of lobal DNA methylation. J. Int Med. Res. 43 758-764 (2015)

148. Metcalfe, D., Van Dijck, S., Parsons, N., Christensen, K $\&$ Perry, D. C. A twin study of Perthes disease. Pediatrics 137, e20153542 (2016).

149. Knoop, J. et al. Identification of phenotypes with different clinical outcomes in knee osteoarthritis: data from the osteoarthritis initiative. Arthritis Care Res. 63, 1535-1542 (2011)

150. Dell'Isola, A., Allan, R., Smith, S. L., Marreiros, S. S. P. $\&$ Steultjens, M. Identification of clinical phenotypes in knee osteoarthritis: a systematic review of the literature BMC Musculoskelet. Disord. 17, 425 (2016).

151. Kraus, V. B., Blanco, F. J., Englund, M., Karsdal, M. A \& Lohmander, L. S. Call for standardized definitions of osteoarthritis and risk stratification for clinical trials and clinical use. Osteoarthrits Cartilage 23 1233-1241 (2015).

152. Deveza, L. A. \& Loeser, R. F. Is osteoarthritis one disease or a collection of many? Rheumatology 57 (Suppl. 4) iv34-iv42 (2017).

153. Hoffman, J. M., Creevy, K. E., Franks, A O'Neill, D. C. \& Promislow, D. E. L. The companion dog as a model for human aging and mortality. Aging Cell 13, e1 2737 (2018).

154. Murchison, E. P. et al. Transmissible dog cancer genome reveals the origin and history of an ancient cell lineage. Science 343, 437-440 (2014).

155. Dingli, D. \& Nowak, M. A. Cancer biology: infectious tumour cells. Nature 443, 35-36 (2006).

156. Paoloni, M. et al. Prospective molecular profiling of canine cancers provides a clinically relevant comparative model for evaluating personalized medicine (PMed) trials. PLoS ONE 9, e90028 (2014).

157. Attur, M. et al. Increased interleukin- $1 \beta$ gene expression in peripheral blood leukocytes is associated with increased pain and predicts risk for progression of symptomatic knee osteoarthritis. Arthritis Rheum. 63, 1908-1917 (2011).

158. Lotz, M. et al. Value of biomarkers in osteoarthritis: current status and perspectives. Ann. Rheum. Dis. 72 1756-1763 (2013).

159. de Bakker, E., Stroobants, V., VanDael, F., van Ryssen, B. $\&$ Meyer, E. Canine synovial fluid biomarkers for early detection and monitoring of osteoarthritis. Vet. Rec 180, 328-329 (2017)

160. Hay, C. W., Chu, O., Budsberg, S. C., Clayton, M. K. \& Johnson, K. A. Synovial fluid interleukin 6, tumor necrosis factor, and nitric oxide values in dogs with osteoarthritis secondary to cranial cruciate ligament rupture. Am. J. Vet. Res. 58, 1027-1032 (1997).

161. Fujita, Y. et al. Direct and indirect markers of cartilage metabolism in synovial fluid obtained from dogs with hip dysplasia and correlation with clinical and radiographic variables. Am. J. Vet. Res. 66, 2028-2033 (2005).

162. Ramírez, S. C., Molano, R. F. S. \& Castaño, G. J. Biomarkers variability in a canine hip osteoarthritis model. Osteoarthritis Cartilage 25, S106 (2017).

163. Messier, S. P., Loeser, R. F., Hoover, J. L., Semble, E. L. $\&$ Wise, C. M. Osteoarthritis of the knee: effects on gait, strength, and flexibility. Arch. Phys. Med. Rehabil. 73, 29-36 (1992).

164. Muller, C. et al. Evaluation of clinical metrology instrument in dogs with osteoarthritis. J. Vet. Intern Med. 30, 836-846 (2016).

165. Brunner, H. I. et al. Health of children with chronic arthritis: relationship of different measures and the quality of parent proxy reporting. Arthritis Rheum. 51, 763-773 (2004).

166. Warden, V., Hurley, A. C. \& Volicer, L. Development and psychometric evaluation of the Pain Assessment in Advanced Dementia (PAINAD) scale. J. Am. Med. Dir. Assoc. 4, 9-15 (2003).

167. Brown, D. C., Boston, R., Coyne, J. C. \& Farrar, J. T. A novel approach to the use of animals in studies of pain: validation of the canine brief pain inventory in canine bone cancer. Pain Med. 10, 133-142 (2009).

168. Brown, D. C., Boston, R. C., Coyne, J. C. \& Farrar, J. T. Ability of the canine brief pain inventory to detect response to treatment in dogs with osteoarthritis. J. Am. Vet. Med. Assoc. 233, 1278-1283 (2008).

169. Walton, M. B., Cowderoy, E., Lascelles, D. \& Innes, J. F. Evaluation of construct and criterion validity for the 'Liverpool Osteoarthritis in Dogs' (LOAD) clinical metrology instrument and comparison to two other instruments. PLOS ONE 8, e58125 (2013).

170. Knazovicky, D., Tomas, A., Motsinger-Reif, A. \& Lascelles, B. D. X. Initial evaluation of nighttime restlessness in a naturally occurring canine model of osteoarthritis pain. PeerJ 3, e772 (2015).

171. Belshaw, Z., Asher, L. \& Dean, R. S. Systematic review of outcome measures reported in clinical canine 
osteoarthritis research. Vet Surg. 45, 480-487

(2016)

172. Sanchez-Bustinduy, M. et al. Comparison of kinematic variables in defining lameness caused by naturally occurring rupture of the cranial cruciate ligament in dogs. Vet. Surg. 39, 523-530 (2010).

173. Moreau, M., Lussier, B., Ballaz, L. \& Troncy, E. Kinetic measurements of gait for osteoarthritis research in dogs and cats. Can. Vet. J. 55, 1057-1065 (2014).

174. Rialland, P. et al. Clinical validity of outcome pain measures in naturally occurring canine osteoarthritis. BMC Vet. Res. 8, 162 (2012).

175. Lascelles, B. D. X. et al. Evaluation of a digitally integrated accelerometer-based activity monitor for the measurement of activity in cats. Vet. Anaesth. Analg. 35, 173-183 (2008)

176. Hansen, B. D., Lascelles, B. D. X., Keene, B. W., Adams, A. K. $\&$ Thomson, A. E. Evaluation of an accelerometer for at-home monitoring of spontaneous activity in dogs. Am. J. Vet. Res. 68, 468-475 (2007)

177. Lascelles, B. D. X. et al. A canine-specific anti-nerve growth factor antibody alleviates pain and improves mobility and function in dogs with degenerative joint disease-associated pain. BMC Vet. Res. 11, 101 (2015)

178. Briley, J. D., Williams, M. D., Freire, M., Griffith, E. H. \& Lascelles, B. D. X. Feasibility and repeatability of cold and mechanical quantitative sensory testing in normal dogs. Vet. J. 199, 245-250 (2014).

179. Williams, M. D. et al. Feasibility and repeatability of thermal quantitative sensory testing in normal dogs and dogs with hind limb osteoarthritis-associated pain. Vet. J. 199, 63-67 (2014).

180. Cook, P. F., Brooks, A., Spivak, M. \& Berns, G. S. Regional brain activations in awake unrestrained dogs J. Vet. Behav. 16, 104-112 (2016).

181. Berns, G. S., Brooks, A. \& Spivak, M. Replicability and heterogeneity of awake unrestrained canine FMRI responses. PLOS ONE 8, e81698 (2013).

182. Arendt-Nielsen, L. et al. Association between experimental pain biomarkers and serologic markers in patients with different degrees of painful knee osteoarthritis. Arthritis Rheumatol. 66, 3317-3326 (2014).

183. Arendt-Nielsen, L. et al. Sensitization in patients with painful knee osteoarthritis. Pain 149, 573-581 (2010).

184. Rialland, P. et al. Association between sensitisation and pain-related behaviours in an experimental canine model of osteoarthritis. Pain 155, 2071-2079 (2014).

185. Knazovicky, D. et al. Widespread somatosensory sensitivity in naturally occurring canine model of osteoarthritis. Pain 157, 1325-1332 (2016).

186. Tomas, A., Marcellin-Little, D. J., Roe, S. C Motsinger-Reif, A. \& Lascelles, B. D. X. Relationship between mechanical thresholds and limb use in dogs with coxofemoral joint OA-associated pain and the modulating effects of pain alleviation from total hip replacement on mechanical thresholds. Vet. Surg. $\mathbf{4 3}$, 542-548 (2014).

187. Aranda-Villalobos, P. et al. Normalization of widespread pressure pain hypersensitivity after tota hip replacement in patients with hip osteoarthritis is associated with clinical and functional improvements. Arthritis Rheum. 65, 1262-1270 (2013).

188. Brown, D. C. Resiniferatoxin: the evolution of the 'molecular scalpel' for chronic pain relie Pharmaceuticals (Basel) 9, E47 (2016).

189. Moreau, M. et al. A posteriori comparison of natural and surgical destabilization models of canine osteoarthritis. Biomed. Res. Int. 2013, 180453 (2013)

190. Hooijmans, C. R., Leenaars, M. \& Ritskes-Hoitinga, M. A gold standard publication checklist to improve the quality of animal studies, to fully integrate the Three Rs, and to make systematic reviews more feasible. Altern. Lab. Anim. 38, 167-182 (2010)

191. Sanga, P. et al. Efficacy, safety, and tolerability of fulranumab, an anti-nerve growth factor antibody, in the treatment of patients with moderate to severe osteoarthritis pain. Pain 154, 1910-1919 (2013).

192. Yu, L. P. et al. Reduction of the severity of canine osteoarthritis by prophylactic treatment with oral doxycycline. Arthritis Rheum. 35, 1150-1159 (1992)

193. Moreau, M. et al. Efficacy of licofelone in dogs with clinical osteoarthritis. Vet. Rec. 160, 584-588 (2007)

194. Iadarola, M. J., Sapio, M. R., Raithel, S. J., Mannes, A. J. \& Brown, D. C. Long-term pain relief in canine osteoarthritis by a single intra-articular injection of resiniferatoxin, a potent TRPV1 agonist. Pain 159, 2105-2114 (2018)

195. Raynauld, J.-P. et al. Protective effects of licofelone, a 5-lipoxygenase and cyclo-oxygenase inhibitor, versus naproxen on cartilage loss in knee osteoarthritis: a first multicentre clinical trial using quantitative MRI Ann. Rheum. Dis. 68, 938-947 (2009).

196. Brandt, K. D. et al. Effects of doxycycline on progression of osteoarthritis: results of a randomized, placebo-controlled, double-blind trial. Arthritis Rheum. 52, 2015-2025 (2005).

197. Arrich, J. et al. Intra-articular hyaluronic acid for the treatment of osteoarthritis of the knee: systematic review and meta-analysis. CMAJ 172, 1039-1043 (2005).

198. Carapeba, G. O. L. et al. Intra-articular hyaluronic acid compared to traditional conservative treatment in dogs with osteoarthritis associated with hip dysplasia. Evid. Based Complement. Alternat. Med. 2016, 2076921 (2016)

199. Kriston-Pál, É. et al. Characterization and therapeutic application of canine adipose mesenchymal stem cells to treat elbow osteoarthritis. Can. J. Vet. Res. $\mathbf{8 1}$ 73-78 (2017)

200. Vilar, J. M. et al. Assessment of the effect of intraarticular injection of autologous adipose-derived mesenchymal stem cells in osteoarthritic dogs using a double blinded force platform analysis. BMC Vet. Res. 10, 143 (2014).

201. Allen, M. J. Advances in total joint replacement in smal animals. J. Small Anim. Pract. 53, 495-506 (2012).

202. Skurla, C. P. et al. Assessing the dog as a model for human total hip replacement. Analysis of 38 canine cemented femoral components retrieved at post-mortem. J. Bone Joint Surg. Br. 87, 120-127 (2005).

203. Clarke, I. C. et al. Development of a ceramic surface replacement for the hip. An experimental Sialon model. Biomater. Med. Devices Artif. Organs 7 , $111-126$ (1979)

204. Harris, W. H. \& Jasty, M. Bone ingrowth into porous coated canine acetabular replacements: the effect of pore size, apposition, and dislocation. Hip 1985 214-234 (1985)

205. Jasty, M. et al. Porous-coated uncemented components in experimental total hip arthroplasty in dogs. Effect of plasma-sprayed calcium phosphate coatings on bone ingrowth Clin Orthop. Relat Res. 280, 300-309 (1992)

206. Kim, Y. H., Kim, J. S., Park, J. W. \& Joo, J. H. Comparison of total hip replacement with and without cement in patients younger than 50 years of age: the results at 18 years. J. Bone Joint Surg. Br. 93, 449-455 (2011).

207. Johnston, S. A., McLaughlin, R. M. \& Budsberg, S. C. Nonsurgical management of osteoarthritis in dogs. Vet. Clin. North Am. Small Anim. Pract. 38 1449-1470 (2008).

208. National Institute for Health and Care Excellence. Osteoarthritis: care and management. NICE.org.uk https://www.nice.org.uk/guidance/cg 177/resources/ osteoarthritis-care-and-management-pdf35109757272517 (2014).

209. Bowen, A \& Casadevall, A Increasing disparities between resource inputs and outcomes, as measured by certain health deliverables, in biomedical research. Proc. Natl Acad. Sci. USA 112, 11335-11340 (2015).

210. Klinck, M. P. et al. Translational pain assessment. Pain 158, 1633-1646 (2017)

211. U.S. Food and Drug Administration. Osteoarthritis: structural endpoints for the development of drugs, devices, and biological products for treatment guidance for industry. FDA.gov http://www.fda.gov/downloads/ Drugs/GuidanceCmplianceRegulatorylnformation/ Guidances/ucm071577.pdf (2018)

212. Eitner, A., Hofmann, G. O. \& Schaible, H.-C Mechanisms of osteoarthritic pain. studies in humans and experimental models. Front. Mol. Neurosci. 10 349 (2017).

213. Hannan, M. T., Felson, D. T. \& Pincus, T. Analysis of the discordance between radiographic changes and knee pain in osteoarthritis of the knee. J. Rheumatol. 27 1513-1517 (2000)

214. Gordon, W. J. et al. The relationship between limb function and radiographic osteoarthrosis in dogs with stifle osteoarthrosis. Vet. Surg. 32, 451-454 (2003).

215. Walsh, K. Chronic pain management in dogs and cats. In Pract 38, 155-165 (2016)

216. Conaghan, P. G. Parallel evolution of OA phenotypes and therapies. Nat. Rev. Rheumatol. 9, 68-70 (2013)

217. Bierma-Zeinstra, S. M. A. \& Verhagen, A. P. Osteoarthritis subpopulations and implications for clinical trial design. Arthritis Res. Ther 13, 213 (2011).

218. Guermazi, A., Roemer, F. W., Haugen, I. K., Crema, M. D. $\&$ Hayashi, D. MRI-based semiquantitative scoring of joint pathology in osteoarthritis. Nat. Rev. Rheumatol. 9, 236-251 (2013).
219. Felson, D. T. et al. Correlation of the development of knee pain with enlarging bone marrow lesions on magnetic resonance imaging. Arthritis Rheum. 56, 2986-2992 (2007).

220. Neogi, T. Structural correlates of pain in osteoarthritis Clin. Exp. Rheumatol. 35 (Suppl. 107), 75-78 (2017).

221. Winegardner, K. R., Scrivani, P. V., Krotscheck, U. \& Todhunter, R. J. Magnetic resonance imaging of subarticular bone marrow lesions in dogs with stifle lameness. Vet. Radiol. Ultrasound 48, 312-317 (2007).

222. Olive, J., d'Anjou, M.-A., Cabassu, J., Chailleux, N. \& Blond, L. Fast presurgical magnetic resonance imaging of meniscal tears and concurrent subchondral bone marrow lesions. Study of dogs with naturally occurring cranial cruciate ligament rupture. Vet. Comp. Orthop. Traumatol. 27, 1-7 (2014).

223. Budsberg, S. C. Torres, B. T., Kleine, S. A Sandberg, G. S. \& Berjeski, A. K. Lack of effectiveness of tramadol hydrochloride for the treatment of pain and joint dysfunction in dogs with chronic osteoarthritis. J. Am. Vet. Med. Assoc. 252, 427-432 (2018).

224. Forster K. E et al. Complications and owner assessment of canine total hip replacement: a multicenter internet based survey. Vet. Surg. 41, 545-550 (2012).

225. Cook, J. L. et al. Proposed definitions and criteria for reporting time frame, outcome, and complications for clinical orthopedic studies in veterinary medicine. Vet. Surg. 39, 905-908 (2010).

226. Takashima, G. $\&$ Day, M. Setting the One Health agenda and the human-companion animal bond. Int. J. Environ. Res. Public Health 11, 11110-11120 (2014).

227. Saunders, L. Z. Virchow's contributions to veterinary medicine: celebrated then, forgotten now. Vet. Pathol. 37, 199-207 (2000)

228. Cassidy, A. in Investigating Interdisciplinary Collaboration: Theory and Practice Across Disciplines (eds Frickel, S., Albert, M. \& Prainsack, B.) 213-236 (Rutgers Univ. Press, 2016).

229. Little, D. et al. Functional outcome measures in a surgical model of hip osteoarthritis in dogs. J. Exp. Orthop. 3, 17 (2016)

230. Conzemius, M. G. \& Vandervoort, J. Total joint replacement in the dog. Vet. Clin. North Am. Small Anim. Pract. 35, 1213-1231 (2005).

231. Lascelles, B. D. X. et al. Evaluation of functional outcome after BFX total hip replacement using a pressure sensitive walkway. Vet. Surg. 39, 71-77 (2010).

232. Dow, C., Michel, K. E., Love, M. \& Brown, D. C Evaluation of optimal sampling interval for activity monitoring in companion dogs. Am. J. Vet. Res. 70 444-448 (2009).

233. Vaughan, L. C. The history of canine cruciate ligament surgery from 1952-2005. Vet. Comp. Orthop. Traumatol. 23, 379-384 (2010).

234. Slocum, B. \& Slocum, T. D. Tibial plateau leveling osteotomy for repair of cranial cruciate ligament rupture in the canine. Vet. Clin. North Am. Small Anim. Pract. 23, 777-795 (1993).

235. Murawski, C. D., van Eck, C. F., Irrgang, J. J., Tashman, S $\& \mathrm{Fu}, \mathrm{F} . \mathrm{H}$. Operative treatment of primary anterior cruciate ligament rupture in adults. J. Bone Joint Surg. Am. 96, 685-694 (2014).

\section{Author contributions}

R.L.M. researched data for the article. R.L.M., R.J.T. and A.A.P. contributed substantially to discussions of content All authors wrote the article and reviewed or edited the manuscript before submission.

\section{Competing interests}

The authors declare no competing interests.

\section{Publisher's note}

Springer Nature remains neutral with regard to jurisdictional claims in published maps and institutional affiliations.

\section{Reviewer information}

Nature Reviews Rheumatology thanks A. Mobasheri and the other anonymous reviewers for their contribution to the peer review of this work.

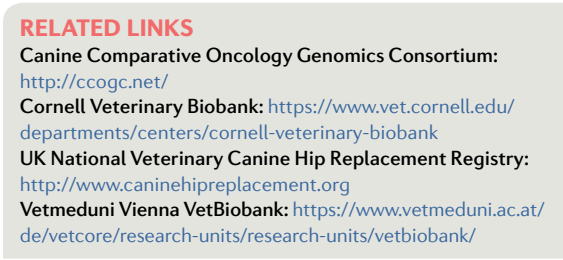

